\title{
The FIFE surface diurnal cycle climate
}

\author{
Alan K. Betts and J. H. Ball \\ Atmospheric Research, Pittsford, Vermont
}

Abstract. We analyze the diurnal cycle of the 2-m thermodynamic data averaged over the First International Land Surface Climatology Project (ISLSCP) Field Experiment site near Manhattan, Kansas, during 1987, using supporting soil moisture data, surface flux data, rainfall, and cloud information. Conserved variable plots are our primary analysis method. We present a summer mean, stratified into dry and wet days, and the monthly seasonal cycle. Further stratifications indicate the control of soil moisture on the surface evapotranspiration, vegetative conductance, and mean diurnal cycle for the boundary layer. We extract composite data sets for the daytime diurnal cycle over grassland in midsummer as a function of soil moisture and show that these are consistent with a mixed layer model for a rapidly entraining boundary layer.

\section{Introduction}

The 1987 First International Land Surface Climatology Project (ISLSCP) Field Experiment (FIFE) collected an extensive data set of surface meteorological data from about 10 portable automatic meteorological (PAM) stations. We edited and averaged these data to a single station mean time series for 6 months, May-October 1987 (Betts et al. [1993], data available in the work of Strebel et al. [1994]). This time series is used here to present a climatology of the mean surface diurnal cycle, associated with the season and forcing functions such as soil moisture, and the surface energy balance. The composite method is used; groups of days will be selected and averaged (using conserved variable plots) to show the impact of season and different physical parameters. By averaging the diumal cycle of many days, we hope to reduce the impact of advective processes, which can produce confusing trends in daily data in midlatitudes. In section 6 we select groups of days in July and August, for which advective influences are reduced. We are not aiming in this paper to test detailed land surface models such as those of Sellers et al. [1989] or Dickinson [1984], but rather to develop data sets for the diurnal cycle of the coupled system of land surface and boundary layer (BL) (including the BL cumulus cloud field), which can be used for the testing and development of coupled parameterizations for global models. We discuss the impact of surface and BL-top processes on the diurnal cycle of equivalent potential temperature, $\theta_{\mathrm{E}}$, which controls the development of cumulus and cumulonimbus convection, and on saturation pressure, $\mathrm{p}^{\text {" (correspond- }}$ ing to the lifting condensation level (LCL) pressure), using a mixed layer model.

There have been several detailed studies of the FIFE surface interaction using time series of fluxes at specific sites. Surface flux measurements were made by 22 stations at 20 sites [Kanemasu et al., 1992]. Smith et al. [1992a] has intercompared these measurements and estimated that the residual measurement uncertainty in the area-averaged fluxes

Copyright 1995 by the American Geophysical Union.

Paper number 94JD03121.

0148-0227/95/94JD-03121\$05.00 is less than $5 \%$. Their paper also shows the dependence of fluxes on soil moisture, cloud fraction, burn treatment, and grazing conditions. We shall use here the continuous time series of surface flux measurements from two sites that were made using a combination of techniques [Smith et al., 1992b; Crosson and Smith, 1992]. Kim and Verma [1990] and Verma et al. [1992)] analyze a single eddy correlation site in detail and provide estimates of vegetative conductance as a function of soil moisture. Stewart and Verma [1992] intercompare two contrasting sites (one grazed and one ungrazed) and show that evaporative fraction (EF) near noon appears to have little dependence on leaf area index (LAI) over a range of LAI from 0.5 to 1.7 . They suggest that feedbacks such as the interactions with the convective boundary layer may reduce the variation in EF. Our analysis draws on all these papers and attempts, by averaging both over the FIFE site and over many days, to see what controls on $\mathrm{EF}$ can be identified in composite data.

This research is prompted by the need to understand the surface forcing over land. One need is for data to test the interactive parameterizations in global models. A direct intercomparison of the diurnal cycle in the FIFE data set and the European Centre forecast model [Betts et al., 1993] led to the identification of many errors in the parameterizations in that global model. The correction of these errors led directly to major improvements in experimental precipitation forecasts over the central United States for the July 1993 floods: this work will be reported elsewhere. However, it is likely that further improvements are possible in both forecast and climate models in the representation of the partly cloudy BL and its interaction with the underlying surface, but so far adequate data sets have been lacking.

\section{Data Used}

The surface meteorological data are an average over the PAM network installed during FIFE 1987. There were initially 10 stations in operation and by the end of the summer, one more had been added. The processing of these data to generate a "FIFE-site" average is discussed by Betts et al. [1993]. The data are 30-min averages of pressure, temperature, mixing ratio, wind speed components, soil 
temperatures at 10 - and 50-cm depth, a radiometric skin temperature, incoming and reflected solar radiation, incoming longwave radiation, net radiation, rainfall, and for most of the period, cloud cover from two sources (a cloud camera at the FIFE site and hourly observations from Marshall Field Air Force Base, roughly $15 \mathrm{~km}$ to the west).

Surface flux measurements were made by 22 stations at 20 sites by both eddy correlation and Bowen ratio methods [Kanemasu et al., 1992]. For four intensive field campaigns (IFCs) (each about 2 weeks in length) all stations operated. From these we averaged the data from 17 stations [Betts and Ball, 1994] to give a representative site average. However, for a seasonal study such as this, these short time periods of data are inadequate. One pair of Bowen ratio stations [Smith et al., 1992b] obtained a continuous time series (from May 25 to October 16, 1987) of radiation and surface flux measurements by a combination of techniques. During the four IFCs, Bowen ratio was measured using fine wire thermo-couples and a single cooled mirror dew point hygrometer. The average of the two stations in this Smith time series for the IFCs agrees quite well with the 17-station average. Between IFCs (and at times of high relative humidity), the dew point hygrometer was not used. Only temperature gradients were then measured, and the surface sensible heat $(\mathrm{SH})$ and latent heat $(\mathrm{LH})$ fluxes were estimated using flux-profile relationships [Smith et al., 1992b]. We used an average of this Smith time series for his two sites, which had stations (grid numbers (IDs)) 2, 38 (1916, 1478), because it is continuous, despite the fact that the measurement techniques were not homogeneous. In fact, for the period between IFC 1 and 2 the sensible heat fluxes at noon calculated by the flux-profile method appear to be too low by about $50 \mathrm{~W} \mathrm{~m}^{-2}$ at local noon. (The $\mathrm{SH}$ time series shows discontinuities at the end of IFC 1 and the beginning of IFC 2, when the method of calculation changes.) The reason is unknown (E. A. Smith, personal communication, 1994), although comparisons between the direct measurements of Bowen ratio in IFC 1 and the fluxes derived by the flux-profile method confirm this bias. Rather than exclude this period (from June 7 to 24) from our initial analysis, we made a simple uniform daytime correction to the $\mathrm{SH}$ and $\mathrm{LH}$ data for this period, sinusoidal in shape with a noon peak of $50 \mathrm{~W} \mathrm{~m}^{-2}$. Our most detailed composites will be based only on July and August data.

About 100 gravimetric soil moisture measurements were taken (roughly five samples at 20 sites) for two subsurface layers (0-5 and 5-10 cm), nearly daily during the IFCs and much less frequently between IFCs. We produced a site average time series of soil moisture for the 0 to $10 \mathrm{~cm}$ layer. Because volumetric soil moisture is often used in large-scale models, we made an approximate conversion. The volumetric soil moisture $\left(\mathrm{SM}_{\mathrm{vol}}\right)$ was calculated from the measured gravimetric fraction $\left(\mathrm{SM}_{\mathrm{grav}}\right)$, assuming a mean wet soil density of 1.1 , using the relation

$$
\mathrm{SM}_{\mathrm{vol}}=1.1 \mathrm{SM}_{\mathrm{grav}} /\left(1+\mathrm{SM}_{\mathrm{grav}}\right)
$$

Soil moisture values were interpolated for days without heavy rainfall, for which no measurements were taken. Between IFCs when measurements were sparse, only general trends can be represented, but this uncertainty does not affect our composite analysis greatly. Profiles of deep soil moisture are available only infrequently at a few sites [e.g. Kim and Verma, 1990], but these are not used here.

\section{Mixed Layer Budgets}

Although we are using averages of measurements made at $2 \mathrm{~m}$ within the superadiabatic layer, their diurnal trends closely reflect the diumal cycle of the mixed layer, until the surface starts to cool in midafternoon. The mixed layer budget equations therefore give a helpful framework for understanding the relative role of fluxes at the surface and by entrainment at the top of the mixed layer (cloud base once small cumulus form). Betts and Ball [1994] analyze the mixed layer budgets using FIFE BL sonde data and show the relationship between mixed layer trends and trends at $2 \mathrm{~m}$, as well as derive estimates of entrainment which we shall use in section 6 .

\subsection{Potential Temperature and Mixing Ratio}

Betts [1992] presented the simplified mixed layer budgets of potential temperature, $\theta$, and mixing ratio, $q$, as (ignoring horizontal advection)

$$
\begin{gathered}
C_{p} \frac{\partial \theta}{\partial t}=\frac{g F_{s \theta}}{P_{i}}\left[1+\frac{\beta_{i}}{\beta_{s}} A_{R} \frac{\left(\beta_{s}-\beta_{v}\right)}{\left(\beta_{i}-\beta_{v}\right)}\right] \\
\lambda \frac{\partial q}{\partial t}=\frac{g F_{s q}}{P_{i}}\left[1+A_{R} \frac{\left(\beta_{s}-\beta_{v}\right)}{\left(\beta_{i}-\beta_{v}\right)}\right]
\end{gathered}
$$

where $\beta_{v} \approx-0.07$ is the slope of the dry virtual adiabat [Betts and Bartlo, 1991] on a $\left(C_{p} \theta, \lambda q\right)$ diagram; $\beta_{s}$ and $\beta_{\imath}$ are surface (subscript s) and inversion level (subscript i) Bowen ratios; and $F_{s}$ denotes a surface energy flux in watts per square meter. $P_{i}, C_{p}$, and $\lambda$ are, respectively, the pressure depth of the mixed layer, the specific heat at constant pressure, and the latent heat of vaporization. The leading terms in (2a) and (2b) are just the surface sensible and latent heat fluxes, which warm and moisten the BL. The second pair of terms, proportional to $A_{R}$, are the entrainment fluxes of typically warm, dry air at the inversion. $A_{R}$ is an entrainment closure parameter which relates the inversion base virtual heat flux to the surface virtual heat flux [Betts, 1973; Carson, 1973; Tennekes, 1973]

$$
F_{i \theta_{v}}=-A_{R} F_{s \theta_{v}}
$$

Equations (2a) and (2b) can be converted using the surface energy budget (surface net radiation, $\boldsymbol{R}_{n}$, and ground storage, $G)$, with the small approximation $(\theta / T) \approx 1$

$$
R_{n}-G=F_{s \theta}+F_{s q}=F_{s q}\left(1+\beta_{s}\right)=F_{s \theta} \frac{\left(1+\beta_{s}\right)}{\beta_{s}}
$$

to give

$$
\begin{gathered}
C_{p} \frac{\partial \theta}{\partial t}=\frac{g\left(R_{n}-G\right)}{P_{i}\left(\beta_{s}+1\right)}\left[\beta_{s}+\beta_{i} A_{R} \frac{\left(\beta_{s}-\beta_{v}\right)}{\left(\beta_{i}-\beta_{v}\right)}\right] \\
\lambda \frac{\partial q}{\partial t}=\frac{g\left(R_{n}-G\right)}{P_{i}\left(\beta_{s}+1\right)}\left[1+A_{R} \frac{\left(\beta_{s}-\beta_{v}\right)}{\left(\beta_{i}-\beta_{v}\right)}\right]
\end{gathered}
$$


The surface forcing and BL depth control these rates of change. However if we divide $(5 a)$ by $(5 b)$, we can see that the direction on a $(\theta, q)$ diagram of the diurnal path of $(\partial \theta / \partial q)$ for the mixed layer depends only on the Bowen ratios $\beta_{s}, \beta_{i}$ and the entrainment rate $A_{R}$. The balance represented by these equations is discussed more extensively by Betts [1994] and Culf [1994]. We shall also show graphs of evaporative fraction (EF) related to the surface energy budget and Bowen ratio by

$$
E F=\frac{-L H}{R_{n}-G}=\frac{1}{1+\beta_{s}}
$$

where the surface available energy is $R_{n}-G$.

\subsection{Saturation Pressure Budget}

Air that is lifted dry adiabatically becomes saturated at its lifting condensation level: we call this its saturation pressure, $p^{*}$, at saturation temperature, $T^{*}$. Since saturation pressure $\mathrm{p}^{\prime \prime}$ is a function of $(\theta, q)$, one can expand

$$
\delta p^{*}=\left(\frac{\partial p^{*}}{\partial \theta}\right)_{q} \delta \theta+\left(\frac{\partial p^{*}}{\partial q}\right)_{\theta} \delta q=\frac{1}{C_{P}}\left(\frac{\partial p^{*}}{\partial \theta}\right)_{q}\left(C_{p} \delta \theta-\beta_{p} \cdot \lambda \delta q\right)
$$

where $\beta_{p^{*}}=(C / \lambda)(\partial \theta / \partial q)_{p^{*}}$ is the slope of the pressure lines on a $\left(C_{p}^{p} \theta, \lambda q\right)$ diagram. Substituting (7) in (5a), (5b) gives the corresponding budget equation for $p^{*}$.

$$
\frac{\partial p^{*}}{\partial t}=\frac{1}{C_{p}}\left(\frac{\partial p^{*}}{\partial \theta}\right)_{q} \frac{g\left(R_{n}-G\right)}{P_{i}\left(\beta_{s}+1\right)}\left[\left(\beta_{s}-\beta_{p}\right)+\left(\beta_{i}-\beta_{p^{*}}\right) A_{R} \frac{\left(\beta_{s}-\beta_{v}\right)}{\left(\beta_{i}-\beta_{\nu}\right)}\right](5 c)
$$

In $(5 c),\left(\partial p^{*} / \partial \theta\right)_{q}$ is negative, so that the first term from the surface fluxes will only increase $p^{*}$ (i.e. bring the mixed layer close to saturation) if

$$
\beta_{s}<\beta_{p^{*}}
$$

At saturation temperatures $\approx 288 \mathrm{~K}, \beta_{p^{*}} \approx 0.5$, with the consequence that (8) is satisfied in FIFE on the days when the surface evapotranspiration is unstressed. The second term is the entrainment term, which mixes down air of low $p^{*}$ and makes the BL less saturated. It generally dominates in the morning hours. However, the fall of $p^{*}$ (rise of LCL) is significantly less on days when (8) is satisfied. The terms in $\left(\beta_{s}-\beta_{p^{*}}\right),\left(\beta_{i}-\beta_{p^{*}}\right)$ in $(5 \mathrm{c})$ may also be thought of as the projection of the surface and inversion fluxes onto the $p^{*}$ isopleths, using the vector diagram concept discussed by Betts [1992] and Culf [1994]. Now $\beta_{p^{*}}$ is related to the wellknown gradient of saturation mixing ratio with temperature

$$
\beta_{p^{*}}=\frac{C_{p}}{\lambda}\left(\frac{\partial \theta}{\partial q}\right)_{p} \cdot \frac{C_{p}}{\lambda S^{*}}=\frac{1}{\epsilon^{*}}
$$$$
\text { where } \quad S^{*}=\left(\frac{\partial q_{s}}{\partial \theta}\right)_{p^{*}} \approx\left(\frac{\partial q_{s}}{\partial T}\right)_{p^{*}}
$$

since $\left(\frac{\theta}{T}\right) \approx 1$ near 1000 mbar. We have added the

superscript ${ }^{*}$ to denote a variable calculated at the saturation level $p^{*}, T^{*}$.
The solution of (5c) for $\partial p^{*} / \partial t=0$ gives a useful reference surface Bowen ratio and corresponding EF, for which $p^{*}$ no longer rises. This can be written [Betts, 1994]

$$
E F^{*}=\frac{1+M}{1+\beta_{p^{*}}+M\left(1+\beta_{v}\right)}
$$

where

$$
M=A_{R}\left(\beta_{i}-\beta_{p^{*}}\right) /\left(\beta_{i}-\beta_{v}\right)
$$

is a measure of the impact of entrainment on the $p^{*}$ budget. For the FIFE data we present here $\beta_{i} \approx-0.26$ at noon, $A_{R} \approx 0.4$ giving $M \approx 1.6$, and a reference $E F^{*} \approx 0.87$, corresponding to a rather low surface Bowen ratio $\beta_{s} \approx 0.15$. Over the FIFE grassland, Bowen ratios are never this low (unless forced by strong dry advection), so that $p^{*}$ generally falls (LCL rises). How rapidly it falls does, however, depend on $\beta_{s}$.

\subsection{The $\theta_{E}$ Budget}

There is a similar equation for the equivalent potential temperature $\left(\theta_{\mathrm{E}}\right)$ budget with $\beta_{w}$ replacing $\beta_{p^{*}}$. The slope of the $\theta_{\mathrm{E}}$ lines is

$$
\boldsymbol{\beta}_{w}=\frac{C_{p}}{\lambda}\left(\frac{\partial \theta}{\partial q}\right)_{\theta_{E}}=-\frac{\theta}{T}=-1
$$

so that the coefficient $\left(\beta_{s}+1\right)$ in (5) is also $\left(\beta_{s}-\beta_{w}\right)$ to this level of approximation. Using (13), the $\theta_{E}$ budget can be written

$$
C_{p} \frac{\partial \theta_{E}}{\partial t}=\frac{R_{n}-G}{P_{i}}\left[1+A_{R} \frac{\left(\beta_{i}+1\right)\left(\beta_{s}-\beta_{\nu}\right)}{\left(\beta_{s}+1\right)\left(\beta_{i}-\beta_{\nu}\right)}\right]
$$

The surface forcing $\left(R_{n}-G\right)$ increases $\theta_{E}$, but this is offset by the entrainment process (the second term in (5d)), which typically brings down lower $\theta_{E}$ air into the mixed layer. In FIFE we found $A_{R} \approx 0.4$, so that for $\beta_{s} \sim 0.4, \beta_{i} \sim-0.26$ (typical of noon when vegetation is unstressed [see Betts and Ball, 1994], this entrainment term $\simeq-0.5$. In the morning, typically $\beta_{i}$ is larger negative until the $\mathrm{BL}$ grows through the nocturnal inversion generated by radiative cooling, and the entrainment term in the $\theta_{E}$ budget is much smaller $(\approx-0.1)$; $\theta_{E}$ rises fastest in the morning, both because of this and because the BL depth $P_{1}$ is small. Conversely, if soil moisture is low and $\beta_{s} \approx 1$ (characteristic of the extended dry period in late July), the rise of $\theta_{E}$ is reduced significantly, both because the entrainment term in (5d) becomes larger negative and because the entrainment increases $B L$ depth. In section 6 we shall show examples of this.

\subsection{BL Growth}

A simple solution for the growth of BL depth, $P_{1}$ can be found by assuming the inversion strength $(\Delta \theta)$ at BL top to remain constant [Betts, 1973. If

$$
\Delta \theta=\theta^{+}-\theta=\text { constant }
$$

where $\theta^{+}$is just above the inversion. Then, as the BL deepens,

$$
\frac{\partial \theta}{\partial t}=\frac{\partial \boldsymbol{\theta}^{+}}{\partial t}=\Gamma^{+} \frac{\partial P_{i}}{\partial t}
$$


where $\Gamma^{+}=-(\partial \theta / \partial p)^{+}$, just above the BL-top inversion. We neglect the small (and partly canceling) effects of subsidence and radiative cooling on changing $\theta^{+}$and $P_{i}$.

Equations (5a), (5b), and (15) can be integrated from an initial morning condition (we used $P_{i}=15 \mathrm{mbar}$ ), to give $\left(\theta, \mathrm{q}\right.$, and $\left.P_{\imath}\right)$ for the ML during the daytime (see section 6.2 below).

\section{Observed FIFE Diurnal Cycle}

In this section we show the mean diurnal cycle for the FIFE 1987 surface data for different broad selections of the data. The most compact presentation of surface thermodynamic data is to show a time sequence of values on a $(\theta, q)$ plot, so we introduce this plot by discussing a June to September average. We show a selection of surface thermodynamic fields and energy fluxes to present a mean picture for the growing season. Full "greenup" of the vegetation appears to have occurred in the third week of May, and the first killing frost appears to have been October 2.

\subsection{Four-Month Average, June - September 1987}

We made one partition of the days in this 4-month period into those with significant rainfall during the daytime (29 days: labelled "wet", roughly $25 \%$ ) and those "dry" days for which the daytime diurnal cycle was not disturbed by rain or heavy overcast. The "wet" group is primarily those with daytime rain, although it includes a few days with heavy overcast but little or no rain. "Overcast" days were defined as having an $R_{n}$ for the 3-hour average from 1700 to 2000 UT (roughly centered on local noon) below a threshold. The thresholds used were $425 \mathrm{~W} \mathrm{~m}^{-2}$ for May, $450 \mathrm{~W} \mathrm{~m}^{-2}$ for June, July, and August, $400 \mathrm{~W} \mathrm{~m}^{-2}$ for September, and 300 $\mathrm{W} \mathrm{m}^{-2}$ in October. (The May and October data are used in section 4.2.) September 13 and 14 were excluded because of missing data. Figure 1 shows the diurnal 2-m temperature cycle. Local noon is around $1820 \mathrm{UT}$, marked by an arrow.

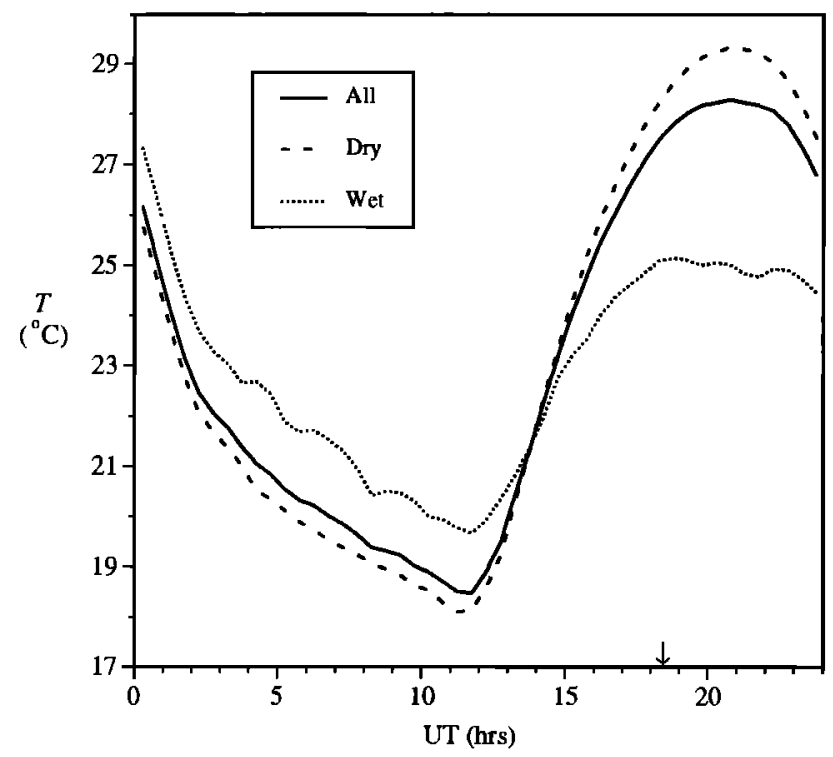

Figure 1. Four-month mean of 2-m diurnal temperature cycle, partitioned into dry and wet days. Local noon is $1820 \mathrm{UT}$, marked by arrow.
The wet-day average, as expected, has a smaller diumal range, with a higher minimum at sunrise, and a lower early afternoon maximum. Figure 2 shows the diurnal 2-m $q$ cycle. Mixing ratio, $q$, falls at night, probably because of dew formation and reaches a minimum at dawn. It rises then for about 4 hours after sunrise as the surface evaporation is trapped in the relatively stable nocturnal boundary layer and then falls to an afternoon minimum as drier air is entrained from above the BL. Similar behavior is seen in both dry and wet averages. In midmorning ( $\sim 1000 \mathrm{LT}$ ), the growing BL breaks through into the nocturnal inversion and typically grows rapidly into a preexisting $\mathrm{BL}$ (see, for example, Grossman [1992]. Cloud base is usually reached, and the entrainment of drier air from above into the mixed layer more than balances the surface evaporation. This change in $\partial q / \partial t$ is associated in (5b) with $\beta_{i}$ (which is negative) becoming smaller in magnitude. Figure 3 shows the daytime path of $P_{\mathrm{LCL}}=\left(p_{s}-p^{*}\right)$ (the pressure height of the lifting condensation level below the surface pressure) for the three averages. The rise of $\boldsymbol{P}_{\mathrm{LCL}}$ corresponds directly to a fall of relative humidity. At sunrise $P_{\mathrm{LCL}} \approx \mathbf{3 0} \mathrm{mbar}$, corresponding to a relative humidity of $90 \%$ at $2 \mathrm{~m}$. On most of these days, boundary layer cumulus clouds form (or more extensive clouds on the wet days) by midmorning, so $\boldsymbol{P}_{\mathrm{LCL}}$ is then representative of the pressure height of cloud base as well as the ML depth $P_{i}$. As expected, the afternoon cloud base is much lower $(\approx 90$ mbar) on the wet days than on the dry days $(\approx 160$ mbar). This saturation pressure budget, $\mathrm{p}^{*}$, is related to the surface evaporation (see Figure 7 below) and entrainment, as discussed qualitatively in section 3.2. Figure 4 shows the daytime rise of $\theta_{E}$. The range is smaller on the wet days (primarily because $R_{n}$ is lower; see Figure 6 below), but a slightly higher mean value is reached near local noon; $\theta_{E}$ falls in the afternoon of the wet-day average, probably because precipitation-driven downdrafts bring low $\theta_{E}$ air into the subcloud layer [e.g. Betts, 1976].

Figures 1 to 4 can be summarized on a single $(\theta, q)$ plot, provided $\theta_{E}$ and $p^{*}$ isopleths are also plotted, and surface pressure is known. Figure 5 shows a daytime $(\theta, q)$ plot for

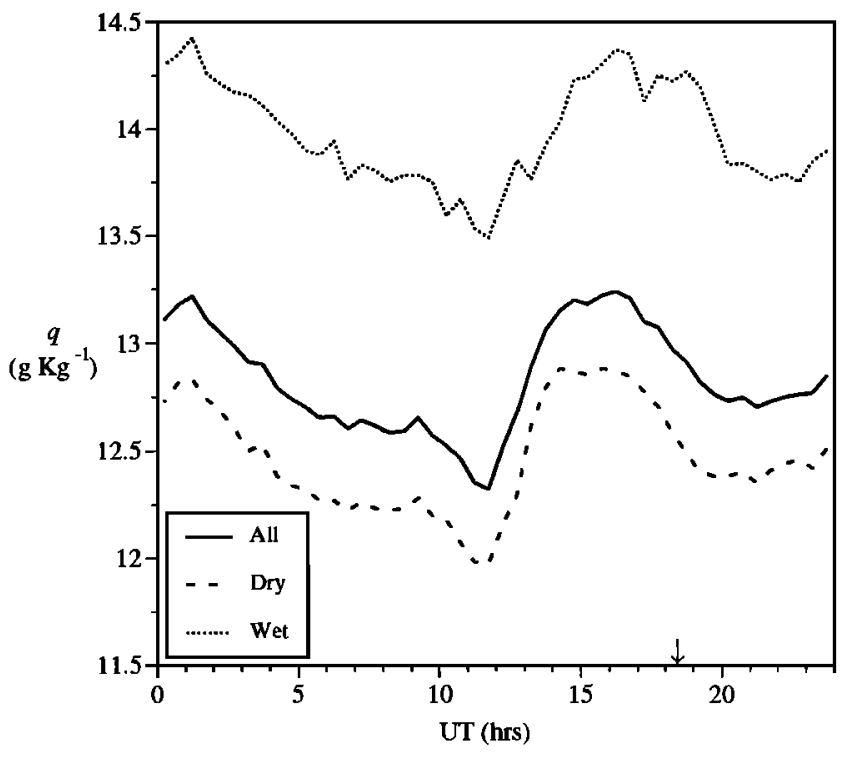

Figure 2. As Figure 1 for 2-m mixing ratio, q. 


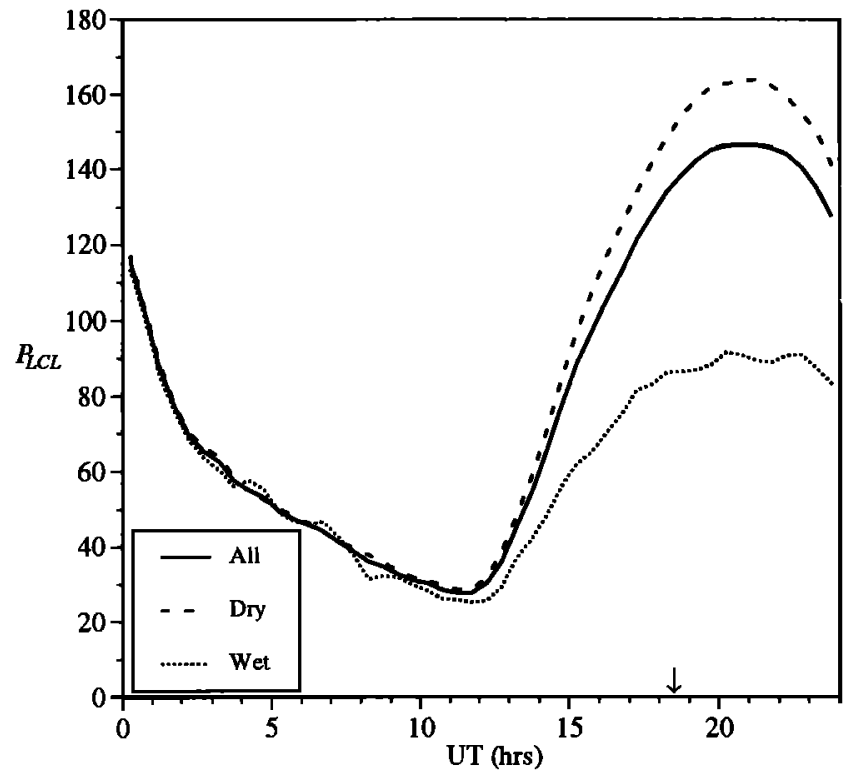

Figure 3. As Figure 1 for daytime path of pressure height to lifting condensation level, $\boldsymbol{P}_{\mathrm{LCL}}$, calculated from 2-m data.

the three averages: all the days and the two subsets of "dry" and "wet" days. Hourly values are plotted from 1145 to 2345 UT (alternate 30-min averages are omitted for clarity). The diurnal patterns are clear. Potential temperature $\theta$ rises from a morning minimum, reaches a maximum near 2100 UT (local solar noon is near 1820 UT), and then falls. The dry days have a cooler minimum (probably less nighttime cloud cover) and a higher maximum (more incoming net radiation). The wet-day average is uniformly moister (by a little over $1 \mathrm{~g} \mathrm{Kg}^{-1}$ ) and has a much smaller temperature range. Mixing ratio $q$ has a weak maximum near $1600 \mathrm{UT}$ (midmorning) but barely changes by $1 \mathrm{~g} \mathrm{Kg}^{-1}$ during the whole daytime cycle, despite the large surface evaporation, because this is balanced over the day by the mixing down of dry air from above.

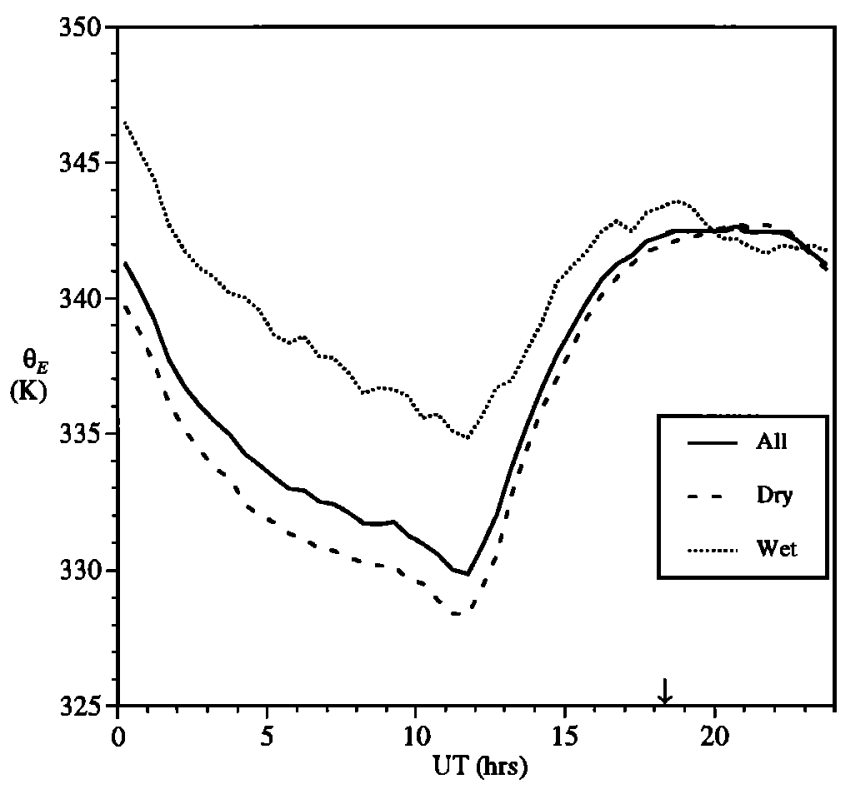

Figure 4. As Figure 1 for equivalent potential temperature $\theta_{E}$.

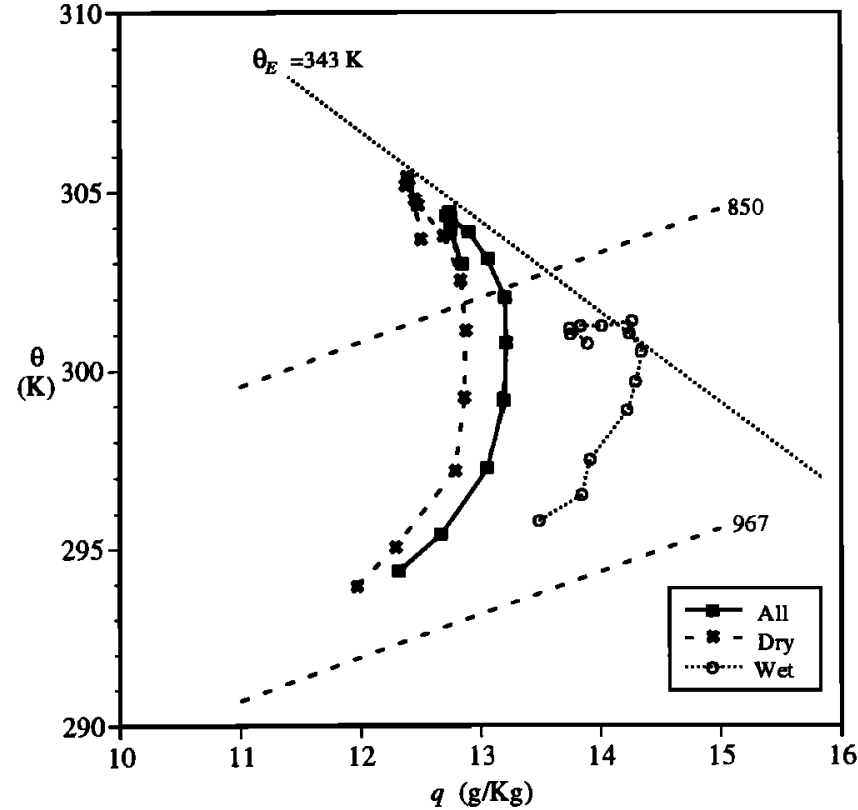

Figure 5. Plot $(\theta, q)$ of hourly data of four-month mean for daytime period: 1145 to 2345 UT.

Figure 6 shows the measured incoming net radiation and the ground heat flux (from Smith et al. [1992b] time series). The surface available energy $R_{n}-G$ peaks at 510 and $300 \mathrm{~W}$ $\mathrm{m}^{-2}$ for the dry- and wet-day averages, respectively. At night, net radiation roughly balances the ground storage. Mean cloud cover (not shown) is around 8/10 on the wet days and only $3 / 10$ on the dry days. The ground heat flux peaks at local noon at about $15 \%$ of the net radiation for the wet average and $17 \%$ for the dry average. The mean surface shortwave albedo at noon from the PAM data is $16 \%$ (not shown).

Figure 7 shows the 4-month average SH and LH fluxes (plotted negative by convention) for the three composites. During the daytime, LH is more than double the SH flux, while at night, both are small $\left(\approx 20 \mathrm{~W} \mathrm{~m}^{-2}\right)$ and roughly cancel each other. Figure 8 shows the surface Bowen ratio

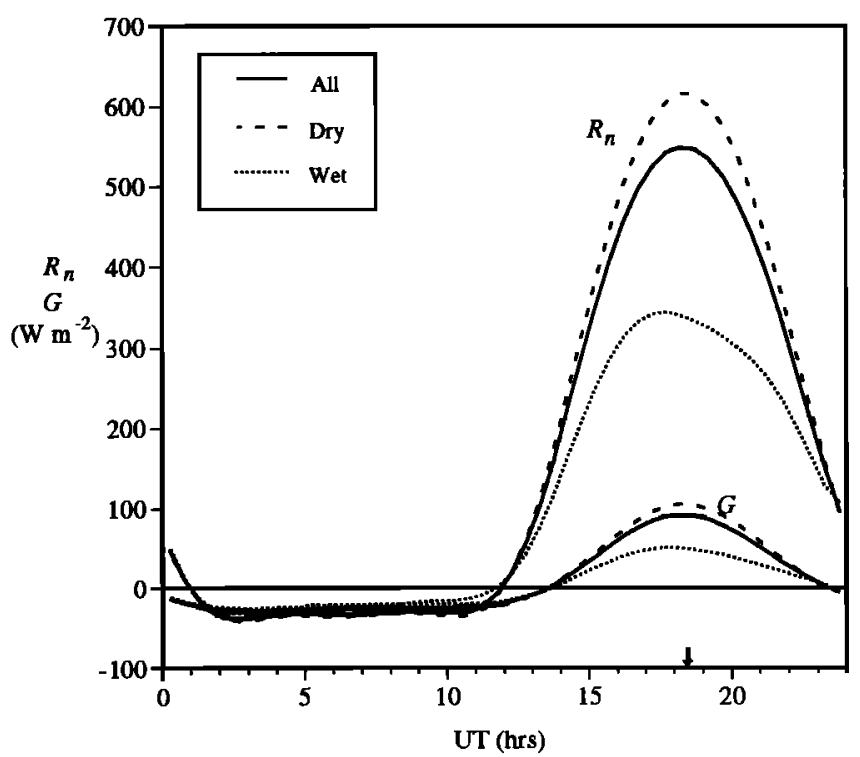

Figure 6. As Figure 1 for surface net radiation and ground heat flux. 


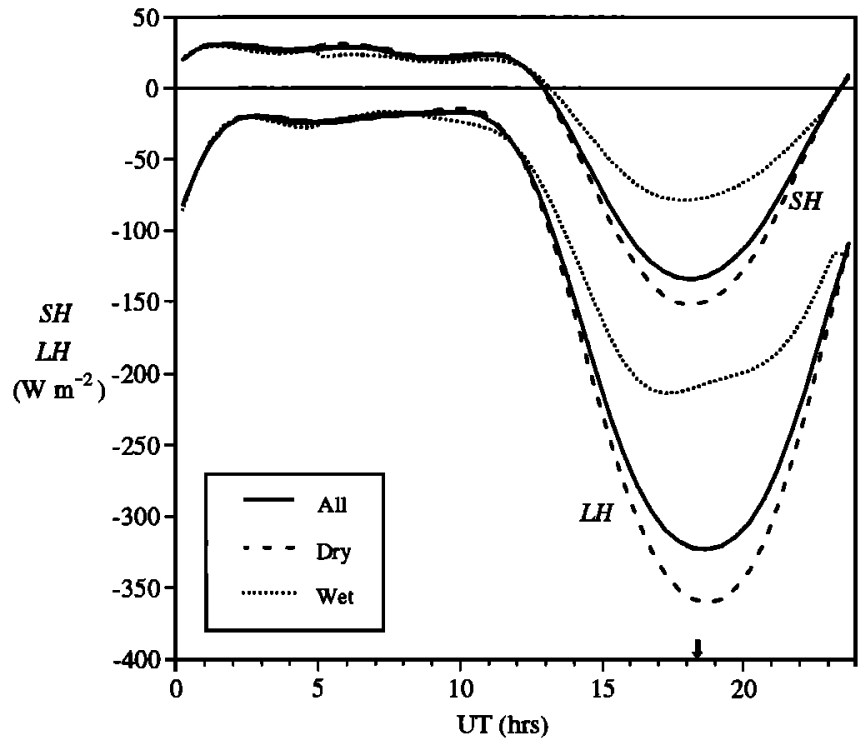

and evaporative fraction (EF). As might be expected EF is larger for the wet average, but the differences are small in these summer averages. Figure 9 shows the difference, $\Delta T_{\text {Rad }}$, between the radiometric surface temperature and the 2-m air temperature over the whole 24-hour period. As might be expected, the skin temperature excess is $2 \mathrm{~K}$ greater on dry days in the daytime and cooler at night (probably because of reduced cloud cover).

\subsection{Seasonal Cycle}

Figure 10 shows the daytime diurnal cycle for the predominantly sunny and dry days from May to October on a $(\theta, q)$ plot. There are 19, 21, 25, 22, 23, 22 days in each average in the sequence from May to October. The selection criteria were near-noon $R_{n}$ above a threshold and no significant daytime rainfall, as mentioned in section 4.1 . Here we

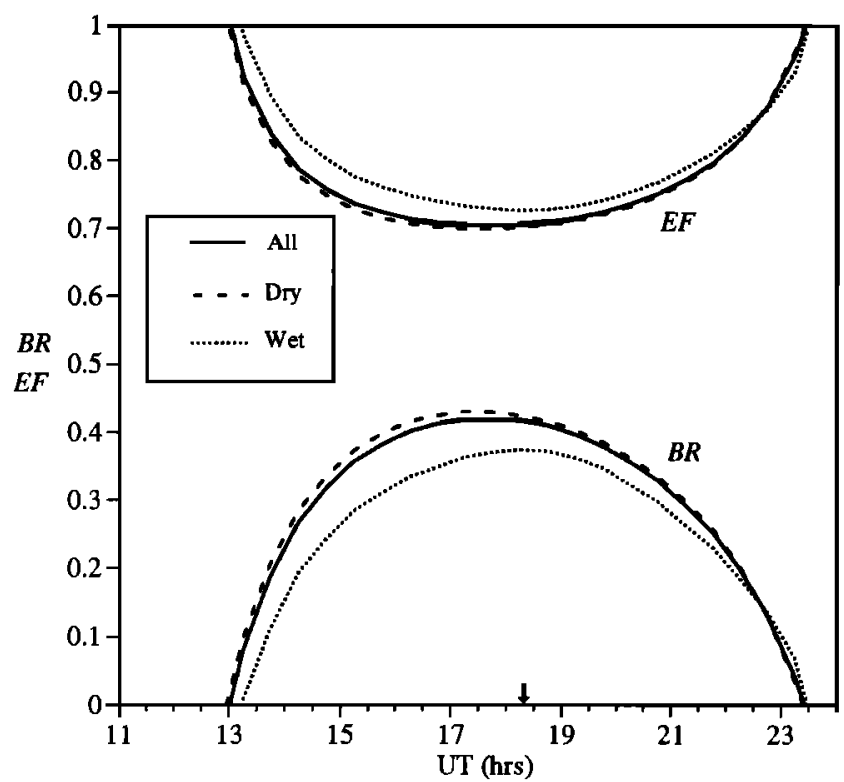

Figure 8. As Figure 1 for surface Bowen ratio and evaporative fraction.

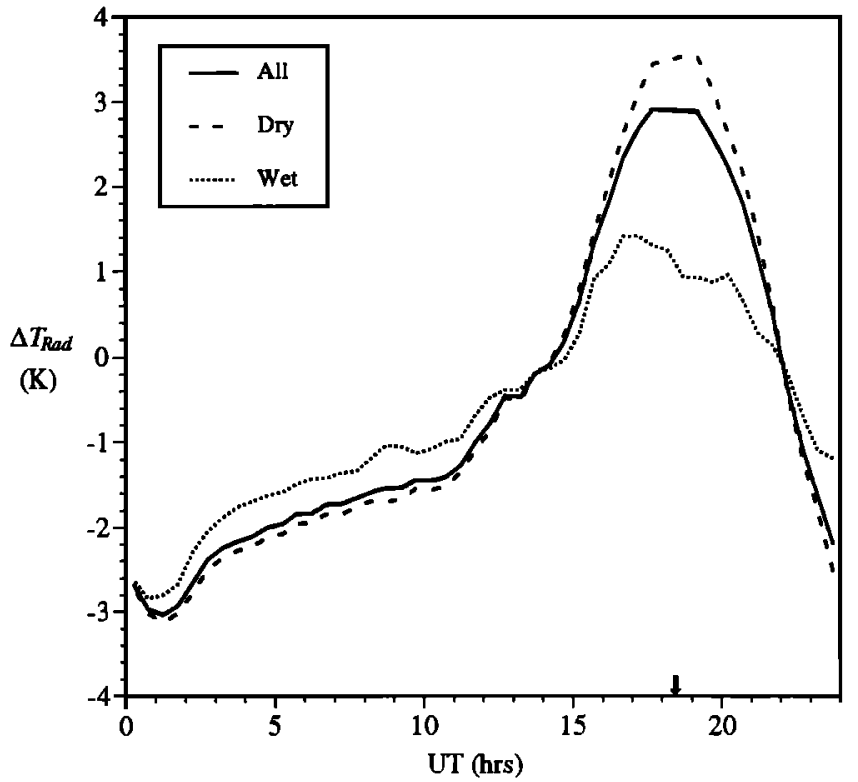

Figure 9. As Figure 1 for difference $\Delta T_{\text {Rad }}$ between radiometric skin temperature and $2-\mathrm{m}$ air temperature.

can see both the diurnal and the seasonal cycle together. The points are again plotted only hourly, starting at $1145 \mathrm{UT}$. October is noticeably drier, after the vegetation has died and evaporation is low. From the $p^{*}=970$ line (corresponding to the surface pressure $p_{s}$ ), it can be seen that at the morning minimum temperature, the $2-\mathrm{m}$ air is about $30 \mathrm{mb}$ from saturation, except in October when it is more unsaturated. The diurnal range of $q$ is relatively small in all months. Like the 4-month mean, there is generally a rise of $q$ in the morning and a fall in the afternoon, although May shows no afternoon fall of $q$. May and June do not reach as low afternoon saturation pressures $\left(p^{*}=800 \mathrm{mb}\right.$ is shown), as the later months of July, August, September, and October. This means a lower mean cloud-base. Probably this reflects the seasonal drying of the surface although changes in upper air thermodynamic structure (through $\beta_{i}$ in (5)) may be in-

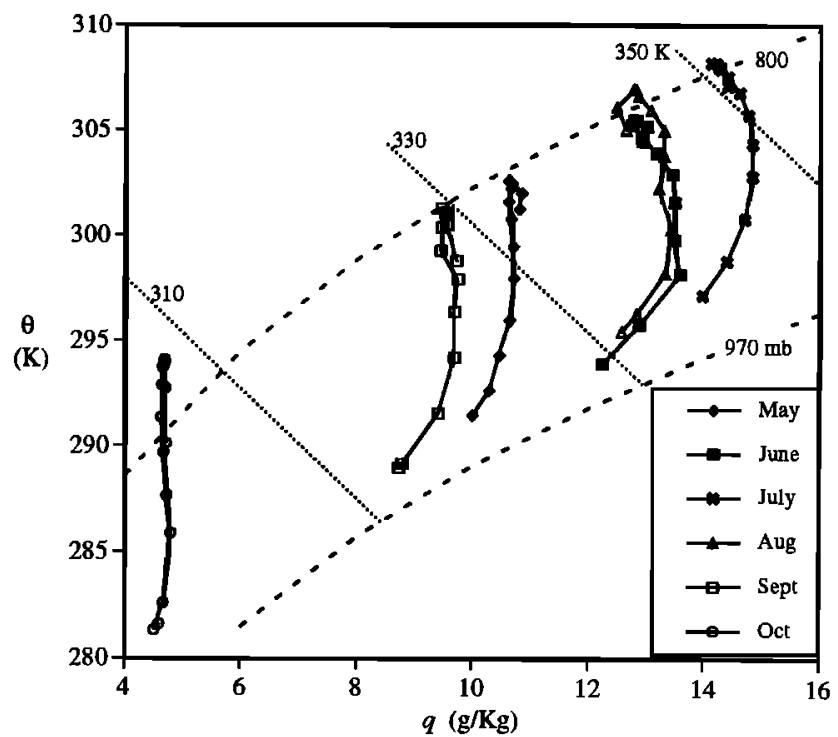

Figure 10. Daytime diurnal cycle from 1145 to 2345 UT for dry day composites from May to October 1987. 
volved. It is clear that the afternoon maximum of $\theta_{E}$ is controlled mostly by the seasonal shift. The isopleths of $\theta_{E}=310,330,350 \mathrm{~K}$ are shown. The rise of $\theta_{E}$ from morning minimum to afternoon maximum is around $14 \mathrm{~K}$ in all months.

\subsection{Partition by Soil Moisture}

We then selected the 94 "dry" days in the period May 26 to September 30 (using the criteria in section 4.1) and partitioned them using the mean volumetric soil moisture measurements in the first $10 \mathrm{~cm}$ of soil. October was excluded because the vegetation has largely died. Admittedly, the first $10 \mathrm{~cm}$ of soil do not constitute the whole root zone, but it is a good indicator of soil moisture, and more important, it is independent of the atmospheric forcing on short timescales (see section 5.2 below). We used four classes: $<15 \%, 15-20 \%, 20-23 \%$, and $>23 \%$ soil moisture by volume.

Table 1 summarizes this stratification, showing the ranges of soil moisture (SM), the number of days in each group, and several mean parameters derived from 3-hour averages from 1700 to $2000 \mathrm{UT}$, roughly centered on local noon. Table 1 shows mean surface Bowen ratio $\left(\beta_{s}\right)$, available energy $\left(R_{n}-G\right)$, mean surface wind speed $V_{s}, \Delta T_{\text {Rad }}$, two estimates of total cloud cover in tenths (the first from Marshall Field, the second from the FIFE whole sky camera, and $P_{\mathrm{LCL}}$. We shall give an indication of the scatter of the data within different classes in section 5.1 below using the near-noon averages.

Figure 11 shows the $(\theta, q)$ summary plot for the four classes. The four averages are not arranged in order in $(\theta, q)$ space, because they contain different mixes of days in different seasons, unlike Figure 22 below. However, they do show a characteristic progression in structure. As soil moisture decreases, the diumal temperature range increases, and the afternoon fall of $q$ increases. This is consistent with decreasing soil moisture increasing the vegetative resistance to evapotranspiration. The extreme dry soil average is one consecutive period of 11 days (July 23-August 2): the driest period of the summer of 1987 .

Figure 12 shows evaporative fraction (EF) for the four averages, and the reference surface $E F^{*}=0.87$ (from (11)) which would keep BL $p^{*}$ constant in the face of entrainment of lower $p^{*}$ air from above [Betts, 1994]. EF generally increases with increasing soil moisture, although the two curves for $\mathrm{SM}>20 \%$ are close and in inverse order. This is also consistent with Smith et al. [1992a] who showed that above a soil moisture threshold of $25 \%$ by mass (equivalent to $22 \%$ by volume in our analysis), EF was nearly constant. However, the surface evaporation, even with wet soils, is insufficient to maintain $p^{*}$ since EF $<E F "$. Figure 13 shows $P_{\mathrm{LCL}}$ : both a measure of the subsaturation of the air at $2 \mathrm{~m}$ and an estimate of the pressure height of cloud base and the mixed layer depth $\boldsymbol{P}_{i}$ in the afternoon. The mean data stratify with the drier soils giving higher $\boldsymbol{P}_{\mathrm{LCL}}$. This rise of $\boldsymbol{P}_{\mathrm{LCL}}$ (fall of $p^{\prime}$ ) is generally consistent with reduced EF from drier soils. Note however that the averages SM1 and SM2 separate in $P_{\mathrm{LCL}}$, but not in EF. At sunrise, conditions are similar, except for the very dry average (SM4), which is much further from saturation (after many days without precipitation). The cloud camera data show more than double the total cloud cover in the two wet soil averages (23 tenths) than the two drier averages (one tenth cloud). The Marshall Field estimates of cloud cover show a similar difference, although they are systematically higher. Figure 14 shows $\Delta T_{\text {Rad }}$, the difference between the radiometric surface $\Delta T_{\mathrm{Rad}}$ and the 2-m air temperature. Again the moist soil averages are close, but with drier soils, $\Delta T_{\text {Rad }}$ increases to a noon peak of $7.5 \mathrm{~K}$ in the driest soil average.

\subsection{Partition by Surface Bowen Ratio}

This stratification of the data, shown in Table 2, is based on the surface Bowen ratio measured by Smith et al. [1992b] for the period 1700 to $2000 \mathrm{UT}$, roughly centered on local noon (1820 UT). A comparison with the stratification by soil moisture is of interest. The first and largest group (BR1) is mostly comprised of days in the two wet soil classes, SM1 and SM2 (28 and 24 days, respectively), with 12 days from the SM3 group. We could not partition this BR1 group further into any coherent subgroups by Bowen ratio. The first two SM1 and SM2 groups were not well separated, and surface Bowen ratio is dependent on atmospheric forcing as well as soil moisture (see section 5.2 below). The second group in Table 2, BR2, contains days from all the $S M$ groups $(2,4,10$, and 3 from SM1, SM2, SM3, and SM4, respectively). The last and driest group BR3 contains eight of the days in SM4 and three from SM3 (August 9-11).

Figure 15 shows the $(\theta, q)$ plot of the three BR groups. They form a sequence with increasing surface BR: there is a larger diumal temperature range and the afternoon fall of $q$ is larger. There is a progression toward a warmer moister mean, probably because SM2 and SM3 contain more of the warmer days in late July and August. Figure 16 shows the 2-m air temperature and the corresponding mean soil temperature at $10-\mathrm{cm}$ depth. The mean upward shift of the diurnal cycle of $T$ with increasing $\beta_{s}$ reflects the increase in

Table 1. Stratification by Volumetric Soil Moisture $0-10 \mathrm{~cm}$

\begin{tabular}{cccccccccc}
\hline Group & $\begin{array}{c}S M \\
\text { Range, \% }\end{array}$ & $\begin{array}{c}\overline{S M} \\
\%\end{array}$ & $\begin{array}{c}\text { No of } \\
\text { Days }\end{array}$ & $\overline{\beta_{s}}$ & $\begin{array}{c}\left(R_{n}-G\right) \\
\mathrm{W} \mathrm{m}^{-2}\end{array}$ & $\begin{array}{c}V_{s} \\
\mathrm{~ms}^{-1}\end{array}$ & $\begin{array}{c}\Delta T_{R a d} \\
\mathrm{~K}\end{array}$ & $\begin{array}{c}\text { Cloud } \\
\text { (tenths) }\end{array}$ & $\begin{array}{c}P_{L C L} \\
\text { mbar }\end{array}$ \\
\hline SM1 & $>23$ & 25.8 & 30 & 0.35 & 505 & 4.25 & 2.5 & $4.3 / 2.9$ & 123 \\
SM2 & $20-23$ & 21.2 & 28 & 0.34 & 492 & 5.25 & 2.7 & $4.5 / 2.3$ & 153 \\
SM3 & $15-20$ & 17.3 & 25 & 0.52 & 496 & 4.65 & 3.8 & $2.5 / 1.1$ & 168 \\
SM4 & $<15$ & 13.4 & 11 & 0.81 & 507 & 5.10 & 6.9 & $2.2 / 0.9$ & 218 \\
\hline
\end{tabular}




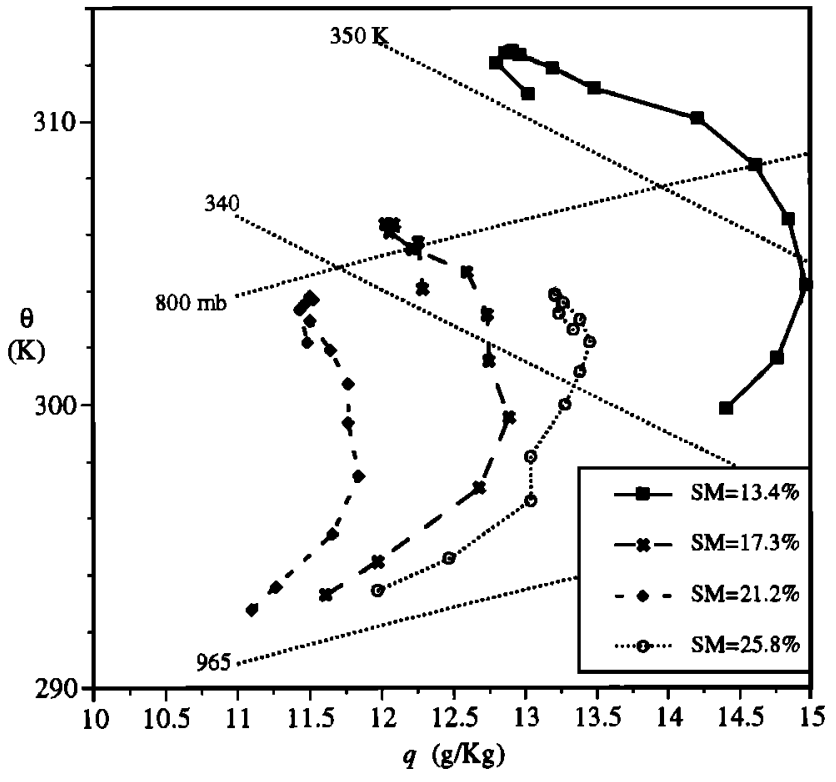

Figure 11. Daytime $(\theta, q)$ plot for summer soil moisture composites.

soil temperature, which is a seasonal effect. The plots of $\boldsymbol{P}_{\mathrm{LCL}}, \theta_{\mathrm{e}}, \Delta T_{\mathrm{Rad}}$, and EF generally show a similar pattern to the stratification by soil moisture. It is clear that despite scatter in the data, stratification by either soil moisture or surface Bowen ratio gives a similar perspective; although neither stratification can separate the regimes of higher soil moisture $(>20 \%)$ and low $\beta_{s}$ which constitute nearly two thirds of the days. Smith et al. [1992a] reached a similar conclusion. Above some soil moisture threshold, evapotranspiration depends primarily on atmospheric parameters, rather than soil moisture controls on vegetative conductance.

\section{Analysis of Noon Data}

\subsection{Averages By Soil Moisture and Bowen Ratio}

Section 4 shows that relationships can be seen in the mean surface diurnal cycle between soil moisture, evaporative

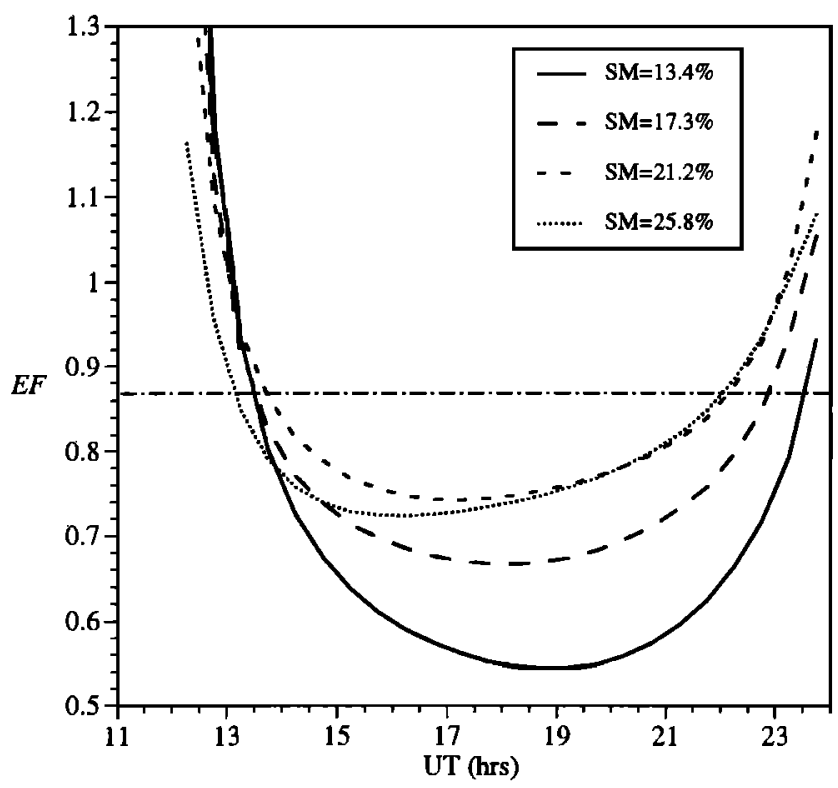

Figure 12. Evaporative fraction for soil moisture composites in Figure 11.

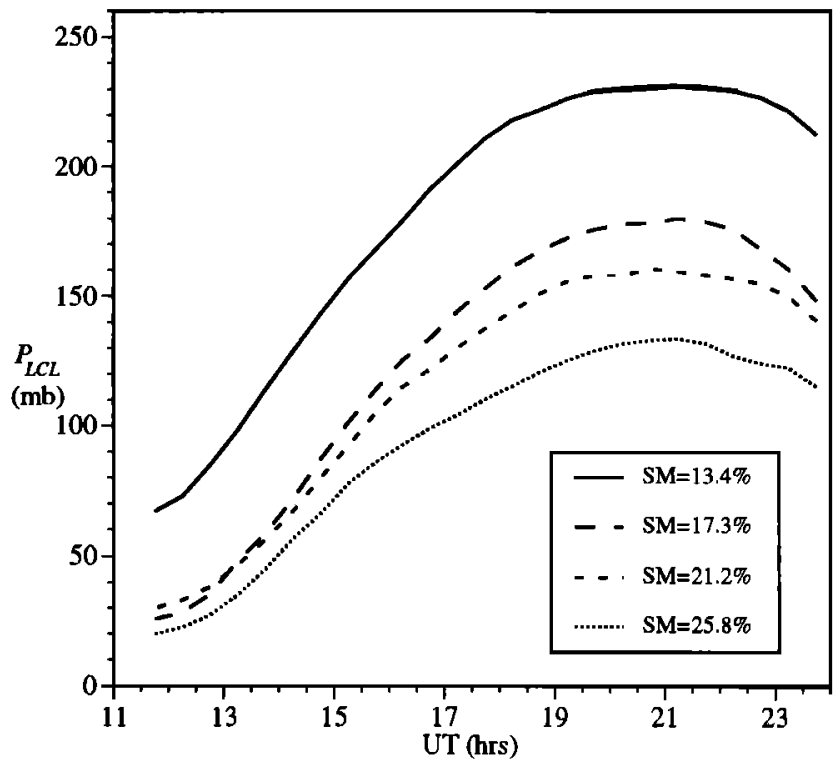

Figure 13. Daytime plot of $P_{L C L}$ for soil moisture composites.

fraction, $P_{\mathrm{LCL}}, \Delta T_{\mathrm{Rad}}$, and other variables. Another way of compositing the days is to look for relationships in the 3hour averages (1700 to 2000 ), which are roughly centered on local noon. (We have already used these averages in Tables 1 and 2). Figure 17 shows $P_{\mathrm{LCl}}, \mathrm{EF}, \Delta T_{\mathrm{Rad}}$, and $V_{\mathrm{s}}$ averaged in $2 \%$ soil moisture bins. The distribution of days is not uniform and the variance (typical standard deviations are shown) in each bin is large (as is the case with all composite analyses in meteorology), but the general trends confirm the pattern shown in Figures $11,12,13$, and 14 in section 4.3. The mean near-noon depth of the mixed layer, as estimated by $P_{\mathrm{LCL}}$, decreases with increasing soil moisture. $\mathrm{EF}$ increases up to $\mathrm{SM} \approx 20 \%$ and then remains constant at $\approx 0.75$, while $\Delta T_{\mathrm{Rad}}$ decreases with soil moisture. The mean wind speed is also shown: it varies around $5 \mathrm{~ms}^{-1}$. As mentioned before, soil moisture, although dependent on past rainfall and evaporation, is independent of the current meteorological forcing. Its variation controls vegetative

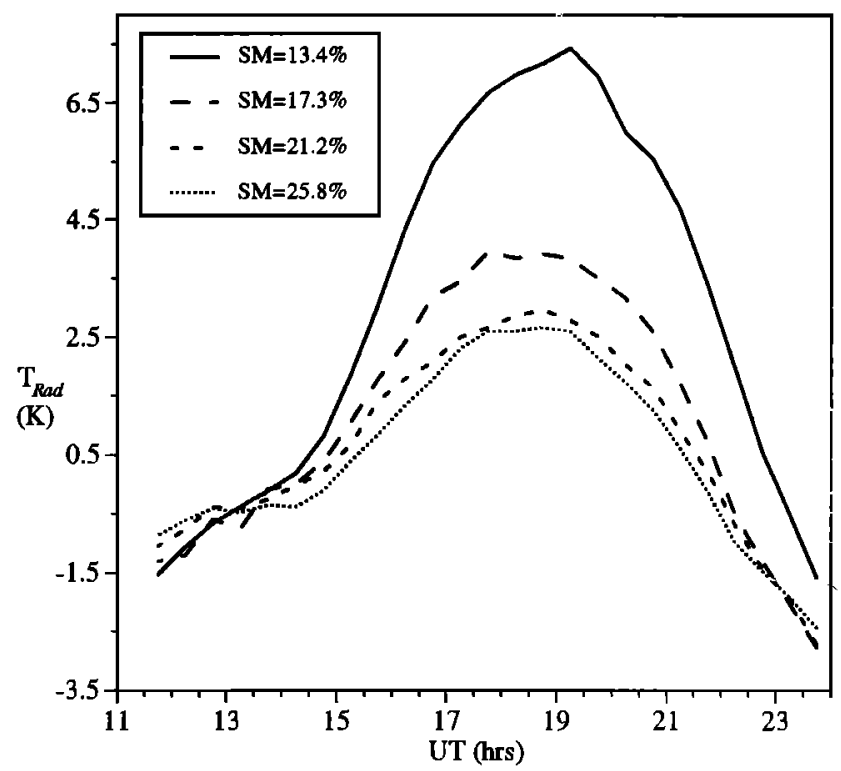

Figure 14. As Figure 13 for $\Delta T_{\text {Rad }}$. 
Table 2. Stratification by Surface Bowen Ratio 1700 to 2000 UT

\begin{tabular}{cccccccccc}
\hline Group & $\begin{array}{c}\beta_{s} \\
\text { Range }\end{array}$ & $\overline{\beta_{s}}$ & $\begin{array}{c}\text { No of } \\
\text { Days }\end{array}$ & $\begin{array}{c}\overline{S M} \\
\%\end{array}$ & $\begin{array}{c}\left(R_{n}-G\right) \\
\mathrm{W} \mathrm{m}^{-2}\end{array}$ & $\begin{array}{c}V_{s} \\
\mathrm{~ms}^{-1}\end{array}$ & $\begin{array}{c}\Delta T_{\text {Rad }} \\
\mathrm{K}\end{array}$ & $\begin{array}{c}\text { Cloud } \\
\text { (tenths) }\end{array}$ & $\begin{array}{c}P_{L C L} \\
\text { mbar }\end{array}$ \\
\hline BR1 & $<0.5$ & 0.32 & 64 & 22.6 & 498 & 4.5 & 2.7 & $4.1 / 2.3$ & 143 \\
BR2 & $0.5-0.8$ & 0.61 & 19 & 18.2 & 500 & 5.6 & 3.9 & $2.9 / 1.5$ & 163 \\
BR3 & $>0.8$ & 0.86 & 11 & 14.3 & 505 & 4.7 & 7.0 & $2.2 / 1.0$ & 213 \\
\hline
\end{tabular}

conductance, and hence EF, although it appears that vegetative conductance and EF becomes insensitive above some threshold of volumetric soil moisture $\approx 20 \%$, as noted by Smith et al. [1992a]. Figure 18 shows similar graphs based on compositing Bowen ratio in 0.1 bins. There are some similarities with Figure 17. For $\beta_{s}>0.4, P_{\mathrm{LCL}}$ increases and SM decreases with increasing $\beta_{s}$, and $\Delta T_{\text {Red }}$ increases over the whole range. There is a suggestion, however (the variances of $P_{\mathrm{LCL}}$ are large), that the lowest $\beta_{s}$ (and highest EFs) are associated not with the highest soil moisture but with drier air (larger $\boldsymbol{P}_{\mathrm{LCL}}$ ), which forces the surface evaporation. This is a local meteorological effect, which illustrates a problem with compositing, using $\boldsymbol{\beta}_{s}$ or EF. In the absense of advective differences, lower surface evaporation will give a drier BL, but the advection of drier air (with low $p^{*}$ ) will force the surface evaporation, provided there is sufficient SM for the vegetation to respond. The next section explores this using the Penman-Monteith equation.

\subsection{Solutions of the Penman-Monteith Model for Surface Evaporation}

The Penman-Monteith model gives useful insight into the relation between atmospheric and soil moisture controls on surface EF or Bowen ratio shown in Figures 17 and 18. The equations for the SH and LH fluxes can be written, following Monteith, 1981, with $\theta_{o}$ as a surface (aerodynamic) potential temperature, as

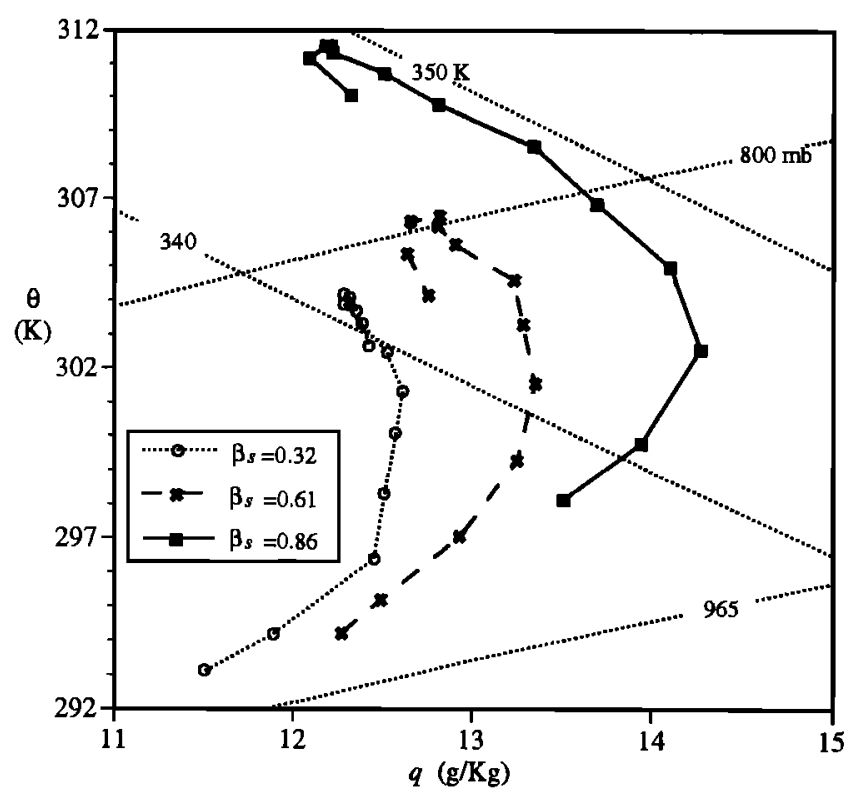

Figure 15. Daytime $(\theta, q)$ plot for Bowen ratio composites.

$$
\begin{gathered}
F_{s \theta}=\rho C_{p} g_{a}\left(\theta_{o}-\theta\right) \\
F_{s q}=\rho \lambda\left(\frac{g_{a} g_{c}}{g_{a}+g_{c}}\right)\left(q_{s}\left(\theta_{o}\right)-q\right)
\end{gathered}
$$

The original Penman-Monteith equation results from the elimination of surface temperature from (16) and the linearization of the saturation mixing ratio curve. We shall approximate $g_{a}$, an aerodynamic conductance, as

$$
g_{a}=C_{T} V_{s}
$$

using a constant transfer coefficient $C_{T}=10^{-2}$ (that is, we neglect dependence on stability). For a FIFE mean wind speed of $V_{s}=4.8 \mathrm{~ms}^{-1}$, this gives $g_{a}=0.048 \mathrm{~ms}^{-1}$. For simplicity, we will treat the vegetative conductance, $g_{c}$, as only a function of soil moisture (that is we neglect stomatal control by vapor pressure deficit). We use a quadratic function (which peaks at $S M=0.30$ )

$$
g_{c}=-0.0178+0.2045 S M-0.341 S M^{2}
$$

which gives for $S M=(0.13,0.26)$ the values of $g_{c}$ of $(0.003$, 0.012) $\mathrm{ms}^{-1}$, representative for FIFE of dry and wet soils [Kim and Verma, 1990]. To solve (16), we specify the surface available energy $R_{n}-G=500 \mathrm{~W} \mathrm{~m}^{-2}$ and vary $\theta, q$, and $P_{\mathrm{LCL}}$ at $2 \mathrm{~m}$ over ranges that are characteristic of the four SM composites in section 4.3. Figure 19 shows as

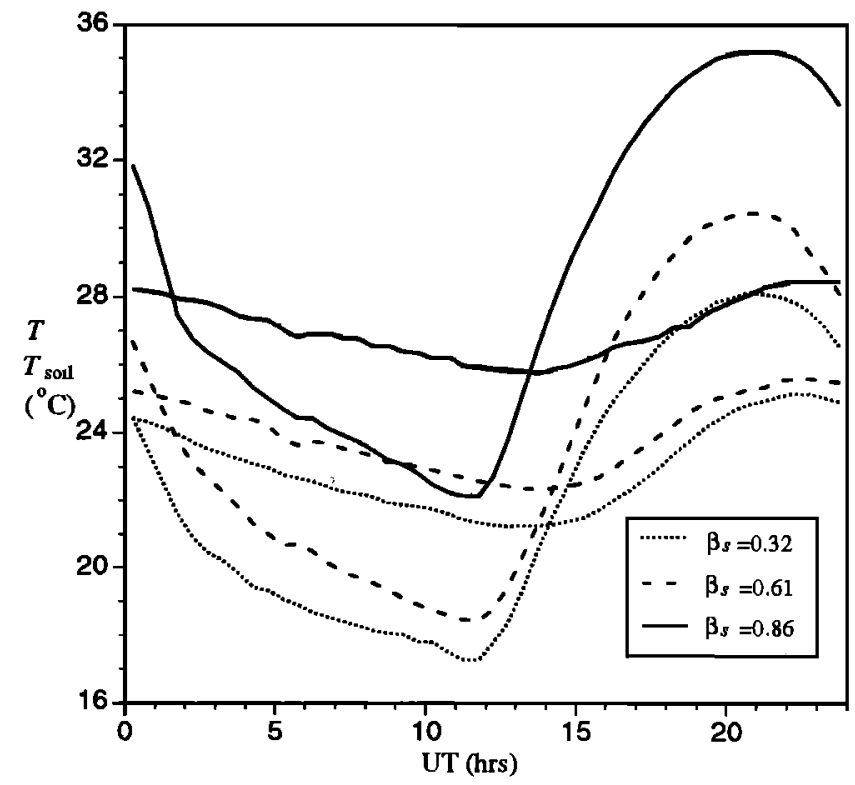

Figure 16. Two-meter air temperature and $10-\mathrm{cm}$ soil temperature for Bowen ratio composites. 


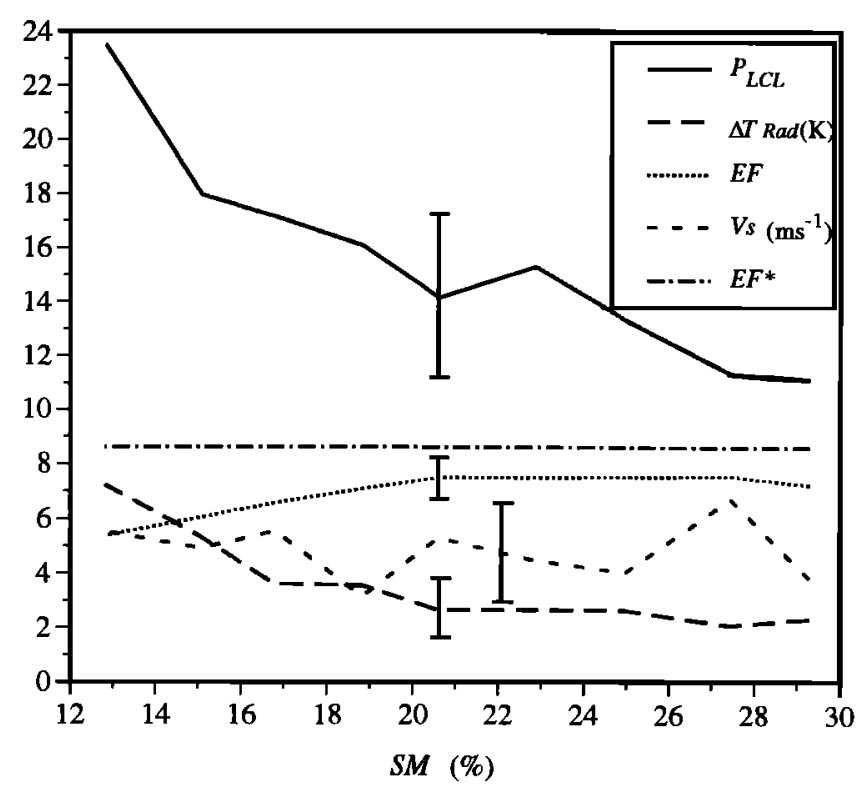

Figure 17. Selected near-noon variables, binned and averaged by daily mean soil moisture. Typical standard deviations shown.

dashed curves the solutions for $\boldsymbol{P}_{\mathrm{LCL}}$ against surface Bowen ratio for four values of soil moisture $(13,17,21$, and $26 \%)$ corresponding to $g_{c}=(0.003,0.007,0.010,0.012)$. For fixed vegetative conductance $g_{c}$ (which here means fixed $\mathrm{SM}$ ), $\beta_{s}$ decreases with increasing $\boldsymbol{P}_{\mathrm{LCL}}$. Larger $\boldsymbol{P}_{\mathrm{LCL}}$ (lower $\mathrm{RH})$ forces surface evaporation and with high vegetative conductances (high soil moisture), $\beta_{s}$ can become negative. The curves are similar for all $g_{c}$, but with decreasing $g_{c}$, the same $P_{L C L}$ gives higher $\beta_{s}$.

Superimposed in Figure 19 (solid curve) are the data for the mean profile of observed near-noon $\boldsymbol{P}_{L C L}$ binned against $\beta_{s}$ from Figure 18 . We see that in range they span the variation of SM from wet to dry. At high soil moistures, where $\left(\partial \beta_{s} / \partial g_{c}\right)_{P_{L C L}}$ is small, the mean data tend to follow the slope of the Penman-Monteith solutions for constant $g_{c}$. In this regime, variations of $P_{\mathrm{LCL}}$ rather than soil moisture are predominantly controlling variations of $\beta_{s}$. However, as SM

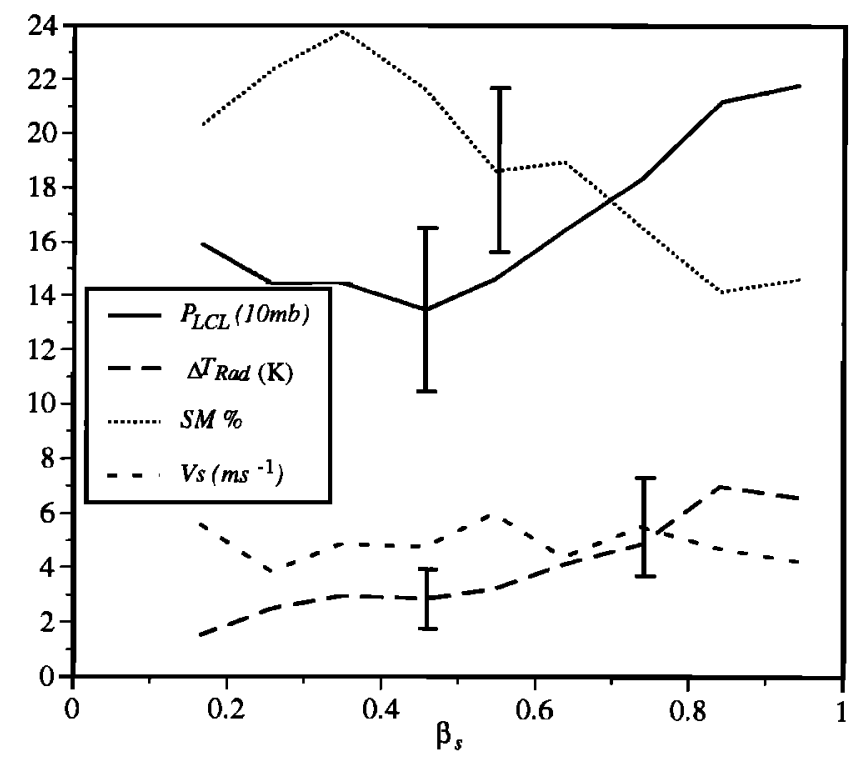

Figure 18. As Figure 17 but binned by surface Bowen ratio.

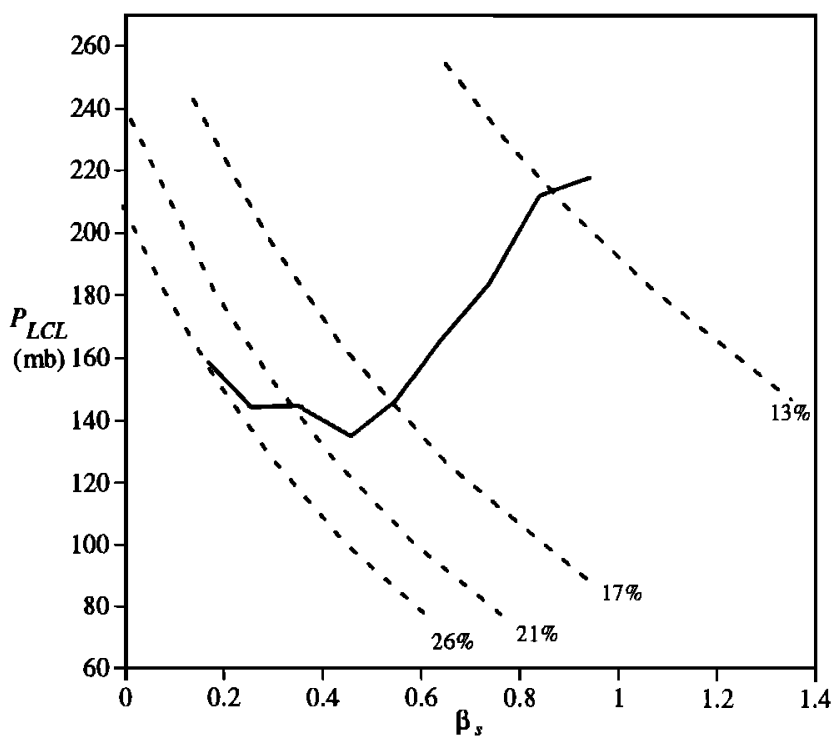

Figure 19. Penman-Monteith solutions (dashed) relating 2-m subsaturation $P_{\mathrm{LCL}}$ to surface Bowen ratio as a function of vegetative conductance (here a function of soil moisture). The data average from Figure 18 are superimposed (solid).

and $\boldsymbol{g}_{c}$ decrease, these become the primary control on $\beta_{s}$, and the surface evaporation controls the mean equilibrium of $\boldsymbol{P}_{\mathrm{LCL}}$. This distinct behavior at the extremes explains in part why Figures 18 and 19 have intermediate minima in $P_{\mathrm{LCL}}$.

\subsection{The $\theta, q$ Classification of Noon Data}

The composites presented so far include all the summer days without significant rain. We now extract a smaller subset of days to develop a reference diurnal data set for further modeling, days which are least affected by cold advection, as well as large variations in net available energy. Figure 20 shows a $(\theta, q)$ plot of the July and August nearnoon averages in three groups. Toward the top right of the

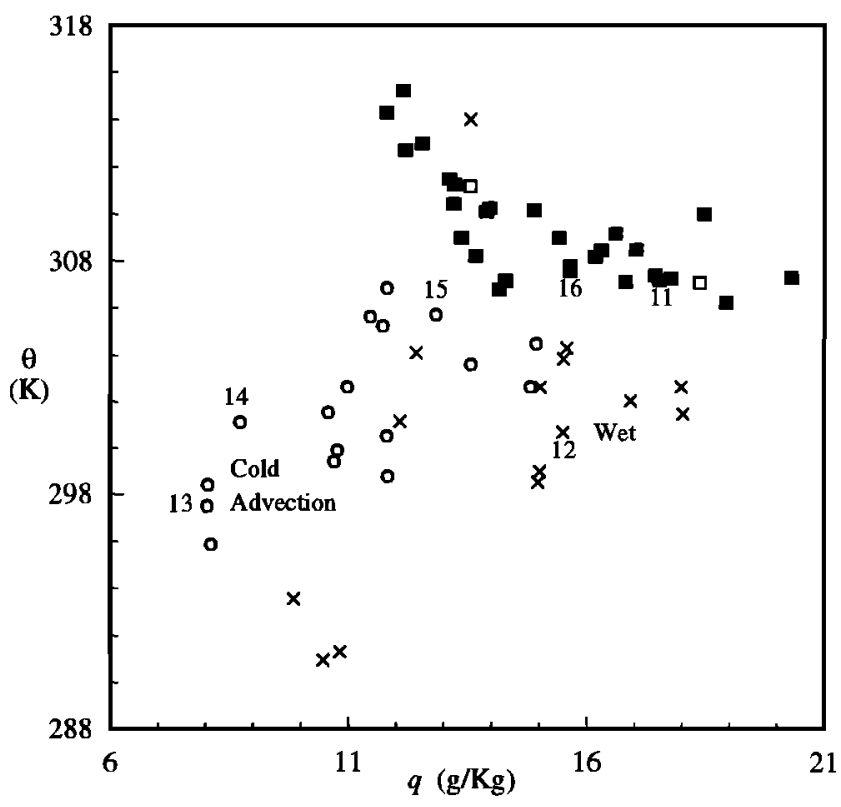

Figure 20. Plot $(\theta, q)$ of near-noon 2-m data for July and August for three groups of data (see text). 


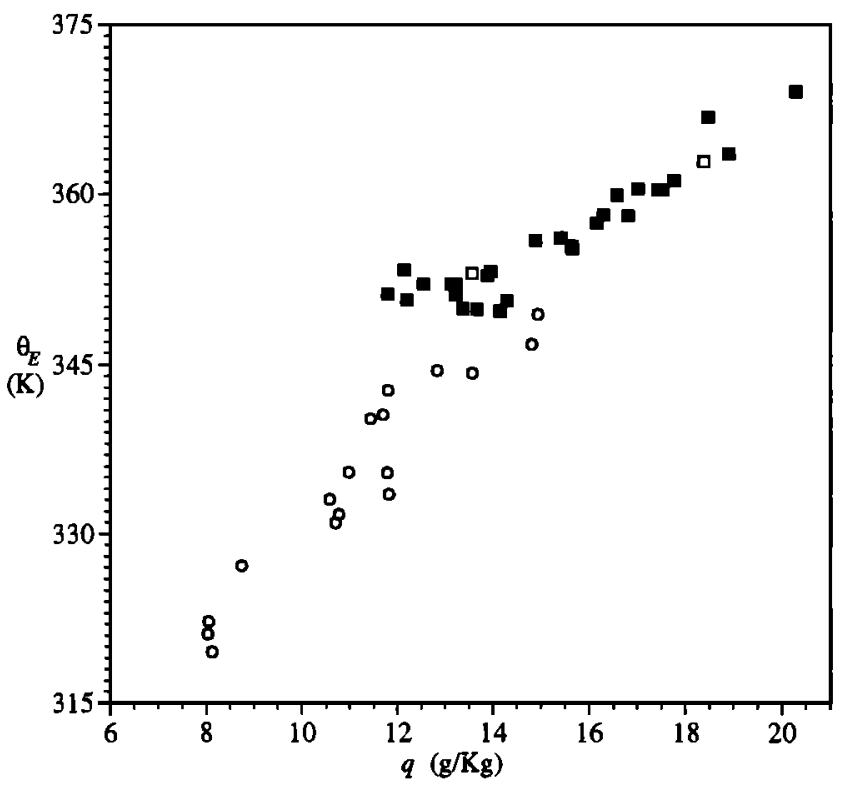

Figure 21. As Figure 20 for $\left(\theta_{E}, q\right)$ plot (excluding wet days).

figure (solid squares) is a band of points which represent the extreme $\theta_{E}$ state reached near noon for different mixing ratios during these two months. This is the group of days which we shall analyze further. The two open squares will be rejected for reasons mentioned below. The second group of points (circles) extending toward colder $\theta$ and drier $q$ are the days when significantly colder air is advected over the FIFE site. One sequence of days, July $11-16$, is labeled to illustrate this. July 11 was a FIFE "golden day", it was followed by a rainstorm on July 12 and the advection of much colder air over the FIFE site for several days. The third group of points (crosses) are the days affected by rain and overcast ("wet" days in section 3.1): we show these to indicate they form a broadly separate group with a lower $P_{\text {LCL }}$ (which has been modified probably by the evaporation of rain [Betts, 1984]). The anomalous upper "wet" point is August 3, when it has just started to rain after weeks of drought. Figure 21 plots the first two groups on a $\left(\theta_{E}, q\right)$ plot to indicate clearly the different coupling between $\theta_{E}$ and $q$ for each group. The afternoon equilibrium of $\theta_{E}$ is an important control on the development of moist convection. Figure 21 is characteristic of the central United States in summer. We now select the subset of 28 days in July and August in the top group (solid squares) for further compositing. We have rejected two extreme events (marked as open squares in this cluster) for specific reasons. The bottom one is August 21, when there was unusually strong advection of warm dry air and the SH flux was near zero. The top one is August 14, the day after $80 \mathrm{~mm}$ of rain fell after a period of low precipitation. The vegetation, which had died back, had not yet recovered, and this day correspondingly has anomalously low evaporation.

\section{Soil Moisture Composites of Selected July Group to August}

\subsection{Data Composites}

We now repeat the partition by soil moisture presented in section 4.3 using this selected group of 28 days in July and August. The data are grouped into the three nearly equal sized classes shown in Table 3. Figure 22 shows the $(\theta, q)$ plot. We now see a clearer pattern in the averages than in Figure 11. Over wet soils the diurnal cycle is shifted toward higher $q$, which increases until 1815 UT (near local noon). The diurnal temperature range is reduced, but $\theta_{E}$ reaches a much higher afternoon maximum of $361 \mathrm{~K}$. In contrast over dry soils, $q$ starts to fall soon after sunrise (after $1315 \mathrm{UT}$ ), $\theta_{E}$ reaches a much lower maximum of $353 \mathrm{~K}$ rather earlier at $1615 \mathrm{UT}$, and $\theta_{E}$ then falls. The average with $15.7 \%$ soil moisture is in between in most respects, although the morning temperature minimum is a little lower for this particular group of 10 days. Figure 22 also contains the diurnal rise of $P_{\mathrm{LCL}}$ for the three groups. The mean surface pressure is 965 mbar. The dry soil group is further from saturation at sunrise and reaches a much higher value $\left(P_{\mathrm{LCL}} \approx 245 \mathrm{mb}\right.$ ) in the afternoon, whereas over wet soils the maximum value of $P_{\mathrm{LCL}}$ is 139 mbar. Figure 23 shows net radiation and ground storage: they differ little among the three groups, in contrast to the dry-wet stratification shown in Figure 6. The net available energy is smaller at noon by about $20 \mathrm{~W} \mathrm{~m}^{-2}$ for the dry soil average, because the greater outgoing longwave (from the higher skin temperature) more than offsets the reduced incoming shortwave (from higher cloud cover). Figure 24 shows the 24-hour pattern of SH and LH fluxes for the three groups. Unlike Figure 7, where the differences were associated largely with a difference in $R_{n}-G$, we see that as soil moisture decreases, the daytime SH flux increases and the LH flux decreases. The flux differences at night are small. Figure 25 shows the corresponding EF. There is a smooth progression with soil moisture, although even with moist soils $E F<E F^{*}$, the value which would maintain $\partial p^{*} / \partial t=0$, until $2100 \mathrm{UT}$. The lowest $\mathrm{EF}$ is progressively later in the day with drier soils. Table 3 indicates the decrease of $\Delta T_{\mathrm{Rad}}=T_{\mathrm{Rad}}-T$ and increase of cloud fraction with soil moisture. Mean wind speed also increases with soil moisture in these groups of days. Together, this set of Figures 22-25 are our best estimate of the

Table 3. Stratification of July to August Subset by Soil Moisture

\begin{tabular}{ccccccccc}
\hline $\begin{array}{c}S M \text { Range } \\
\%\end{array}$ & $\begin{array}{c}\overline{S M} \\
\%\end{array}$ & $\begin{array}{c}\text { No of } \\
\text { days }\end{array}$ & $\overline{\beta_{s}}$ & $\begin{array}{c}\left(R_{n}-G\right) \\
\mathrm{W} \mathrm{m}^{-2}\end{array}$ & $\begin{array}{c}V_{s} \\
\mathrm{~ms}^{-1}\end{array}$ & $\begin{array}{c}\Delta T_{\text {Rad }} \\
\mathrm{K}\end{array}$ & $\begin{array}{c}\text { Cloud } \\
\text { (tenths) }\end{array}$ & $\begin{array}{c}P_{L C L} \\
\text { mbar }\end{array}$ \\
\hline$>20$ & 23.4 & 10 & 0.36 & 527 & 7.2 & 1.6 & $4.2 / 2.9$ & 127 \\
$14-20$ & 15.7 & 10 & 0.65 & 528 & 5.9 & 4.9 & $3.2 / 1.4$ & 161 \\
$<14$ & 13 & 8 & 0.85 & 505 & 5.3 & 7.3 & $1.7 / 0.6$ & 231 \\
\hline
\end{tabular}




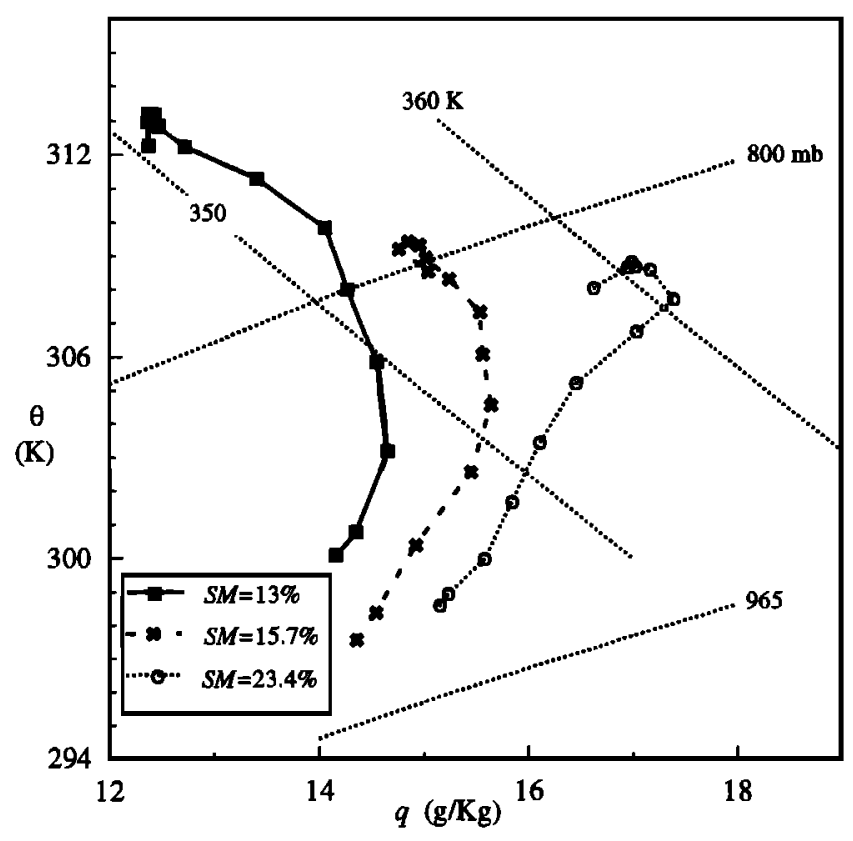

Figure 22. Plot $(\theta, q)$ of selected 28 days from July and August 1987 , composited by soil moisture.

climatological diumal variation of near-surface parameters as a function of soil moisture in midsummer for the FIFE area. The complete data sets are available from the authors on diskette for further modeling studies.

\subsection{Mixed Layer Model Simulation}

We now integrate the ML model equations (5a), (5b), and (15) (presented in section 3) to see how well we can simulate the diumal cycle of the observed composites in Figure 22. As input we specified $\Gamma^{+}=5 \mathrm{~K} / 100 \mathrm{mbar}$, as well as values of $A_{R}$ and $\beta_{i}$ based on Betts and Ball, [1994, herinafter referred to as BB94], and fitted approximate analytic functions to the measured surface available energy $R_{n}-G$ and $\beta_{s}$. Table 4 gives the formulas used. Time is in UT,

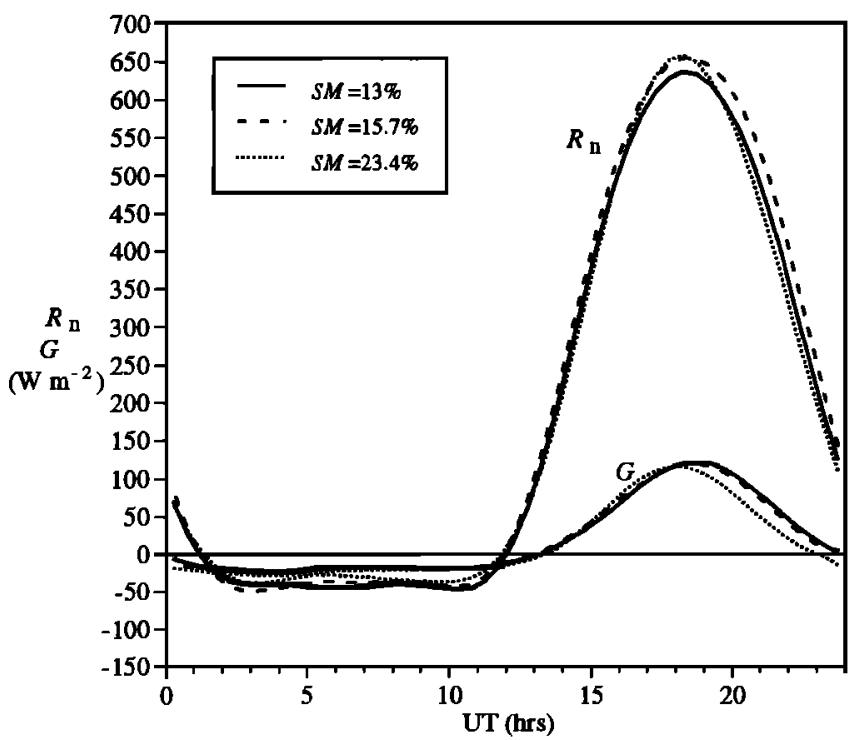

Figure 23. Net radiation and ground heat flux for groups of days in Figure 22.

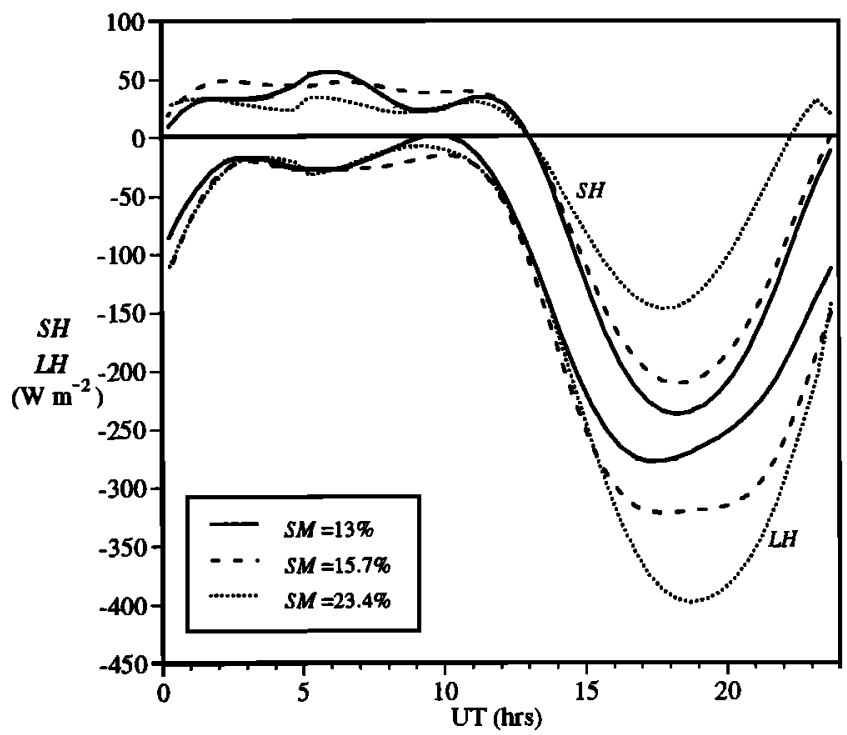

Figure 24. As Figure 23 for surface sensible heat and latent heat fluxes.

with local noon taken here as 18.5 UT. The surface forcing is quite well known, and the stability, $\Gamma^{+}$, above the $M L$ is a representative value for the day. The biggest uncertainty in the integration comes from the parameters related to the entrainment process, so we shall discuss the sensitivity to $A_{R}$ and $\beta_{i}$.

The mean diurnal cycles shown in Figure 22 result both from the differences in surface forcing and from the differences in $(\theta, q)$ at sunrise. We first removed the latter difference. Figure 26a replots the three diumal paths in Figure 22 with $\theta, q$ shifted uniformly for each composite to start at the same origin: the mean $(\theta, q)$ at 1245 UT (just before the surface SH becomes upward at 1300 UT). Figure $26 \mathrm{~b}$ shows the integration of the ML model from the same initial condition with $\beta_{i}=-0.26$ and $A_{R}=0.4$, representative of the values found in the budget study of BB94. There is some qualitative agreement with Figure 26a (although the curvatures of the plots differ considerably), considering that

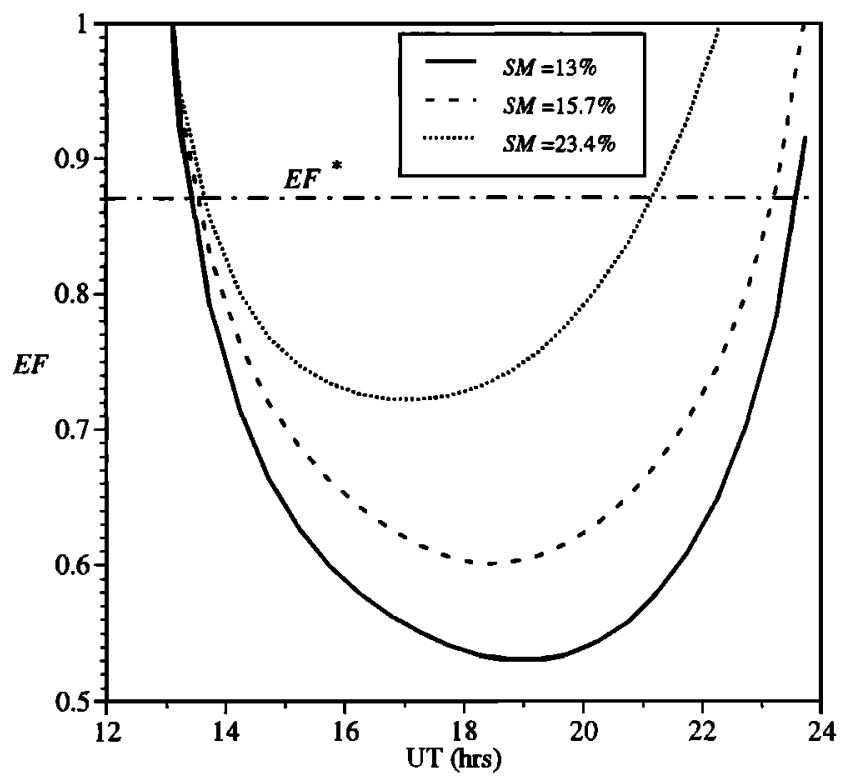

Figure 25. As Figure 23 for daytime evaporative fraction. 
Table 4. Idealized Mixed Layer Model Parameters

\begin{tabular}{ccc}
\hline$\beta_{s} \max$ & $\beta_{s}$ & $\left(R_{n}-G\right)$ \\
\hline 0.39 & $0.39\left(1-(\mathrm{UT}-17.25)^{2} / 25\right)$ & $541\left(1-(\mathrm{UT}-18.50)^{2} / 36\right)$ \\
0.66 & $0.66\left(1-(\mathrm{UT}-18.25)^{2} / 33\right)$ & $536\left(1-(\mathrm{UT}-18.50)^{2} / 36\right)$ \\
0.87 & $0.87\left(1-(\mathrm{UT}-18.50)^{2} / 34\right)$ & $515\left(1-(\mathrm{UT}-18.50)^{2} / 36\right)$ \\
\hline
\end{tabular}

the data are at $2 \mathrm{~m}$ within the superadiabatic layer and the model represents a ML average. However the middle curve for $\beta_{\mathrm{s}}(\max )=0.66$ is too dry in the afternoon in comparison with the data, and the curve representing wet soils $\left(\beta_{\mathrm{s}}(\max )=0.39\right)$ becomes too moist in late afternoon. This may be because clouds continue to mix down dry air after the surface buoyancy flux becomes negative; this process is not included in the ML model. However, the general agreement is encouraging, considering the representativity of the composites (which are averages over only $\approx 10$ days) is unknown, and there is considerable uncertainty in the MLtop parameters. Specifically, the ML model is very sensitive to $A_{R}$. Many earlier modeling studies used $A_{R}=0.2$ [e.g. Stull, 1988]. Figure 26c shows the solutions changing only $A_{R}$ to 0.2 . It is clear that these solutions are completely inconsistent with the 2-m data, confirming that over the FIFE area the entrainment parameter is high, with $A_{R} \approx 0.4$ [Betts, 1992; BB94]. Clarke [1990] and Culf [1992] have also noted similar high values of entrainment. How well is $\beta_{1}$ known? Betts and Ball [1994] estimated $\beta_{\mathrm{i}}$ using data from the ML budgets, from the inversion rise, and from sonde profiles. A simple average of their values is $\beta_{1}=-0.26 \pm 0.09$, indicating the considerable uncertainty (although some of their more extreme values could be rejected on other grounds of inconsistency). Their data also suggest that $\beta_{\text {, }}$ increases during the day from perhaps -0.45 in early morning to an afternoon maximum $\approx-0.2$, but the evidence is limited. If we included a time varying $\beta_{\text {, in the }}$ iL model, the afternoon end points are little changed (for the

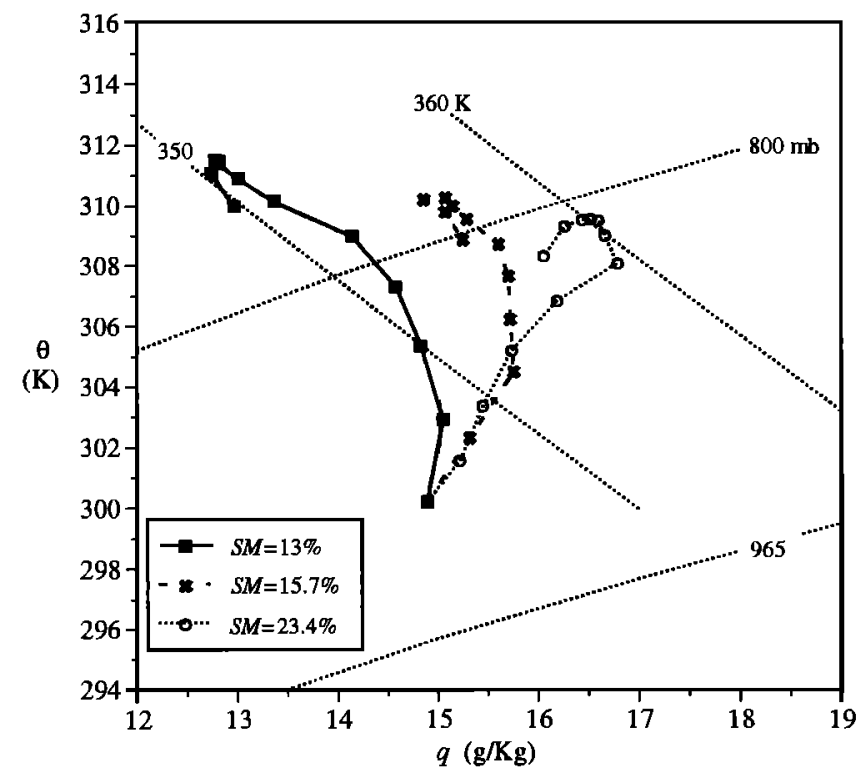

Figure 26a. Replot of Figure 22 with data shifted to common origin at $1245 \mathrm{UT}$. same mean $\beta_{i}$ ), although the path changes. Consequently, considering the uncertainty fof $\beta_{i}$, we will only use mean values here for illustration. The last panel, Figure 26d, shows the solutions with the larger value of $\beta_{\mathrm{i}}=-0.35$ and $A_{R}=0.4$. Clearly, these model solutions are a little too moist (although only marginally so for $\left.\beta_{\mathrm{s}}(\max )=0.66\right)$. Comparing Figures 26c and 26d shows reducing $A_{R}$ can give qualitatively the same solutions as increasing $\beta_{i}$. Indeed, the solutions with $\beta_{i}=-0.35, A_{R}=0.4$, are close to these with $\beta_{t}=-0.26, A_{R}=0.3$ (not shown). Going a step further, if $\beta_{t}$ is reduced to -0.17 , then the solutions with $A_{R}=0.2$ are close to those with $\beta_{t}=-0.26, A_{R}=0.4$.

We conclude that the surface diurnal path of $(\theta, q)$ gives an indirect estimate of the entrainment process, although we cannot separate $A_{R}$ and $\beta_{1}$ using the surface data alone. If we introduce an estimate of $\beta_{i} \approx-0.26$ from the $\mathrm{BL}$ studies in BB94, this surface data analysis confirms that $A_{R} \approx 0.4$. However, we have no upper air data for any of the days in the dry soil set $(S M=13 \%)$ and only one day in the $\mathrm{SM}=15.7 \%$ set, so the BB94 data are actually representative of only the wet soil composite. A related uncertainty is the influence of clouds both on $A_{R}$ and the inversion level Bowen ratio. The wet soil group has a greater cloud fraction and this might result in either a large value of $A_{R}$ or a smaller value of $\left|\beta_{i}\right|$ because the air ascending through cloud base is typically warmer and moister than the mixed layer average. In general, our cloud data from FIFE are inadequate to properly define the diumal cycle of cloudiness and cloud base properties.

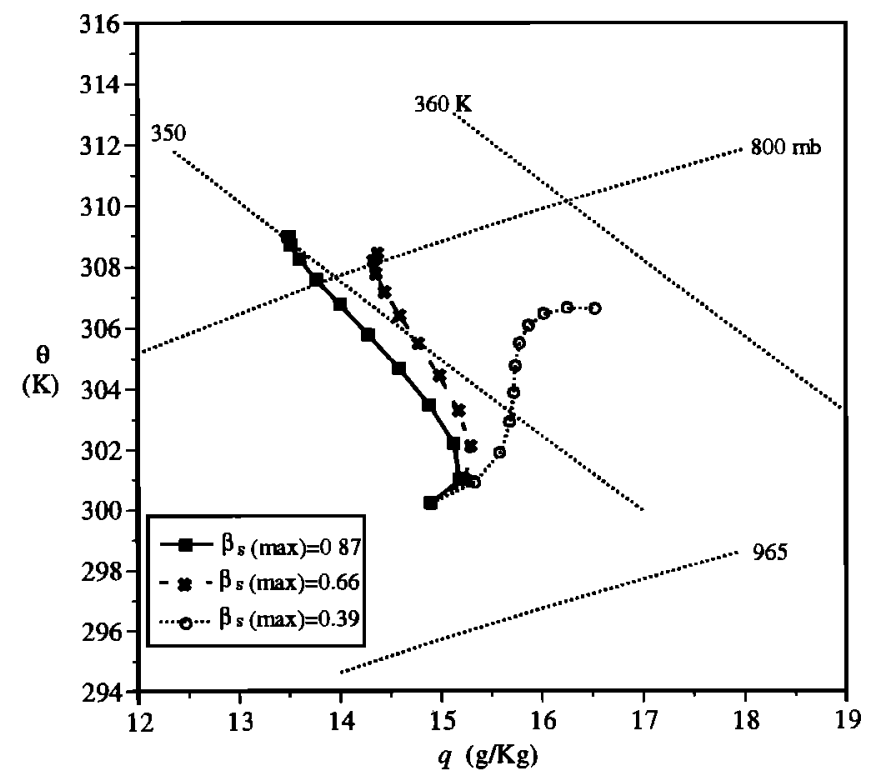

Figure 26b. Integration of mixed layer model from $1245 \mathrm{UT}$ mean for $A_{R}=0.4$ and $\beta_{t}=-0.26$. 


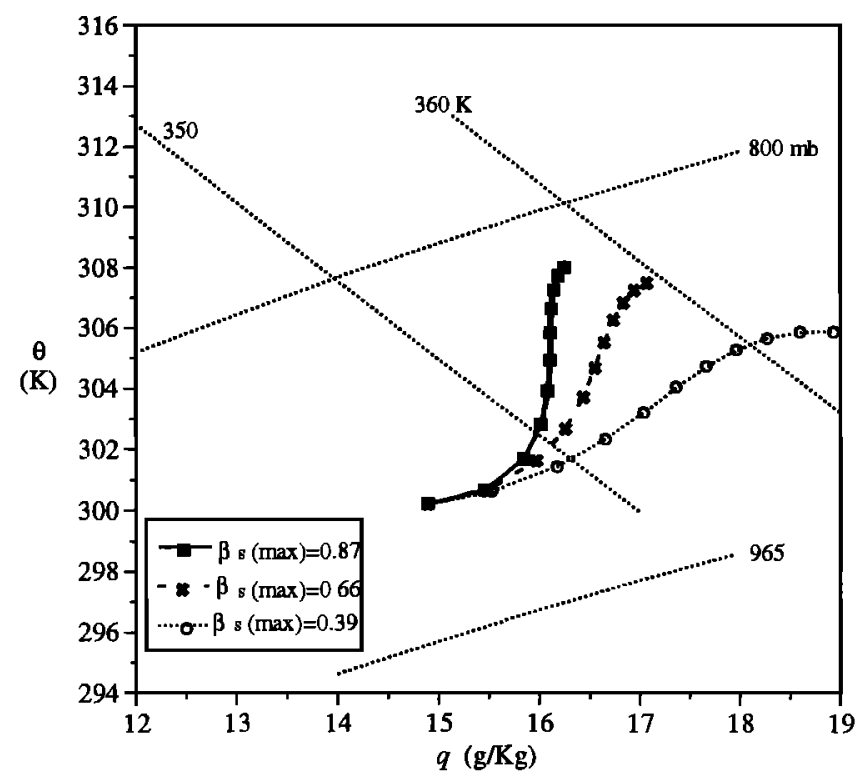

Figure 26c. As Figure 26b for $A_{R}=0.2$.

\section{Summary and Conclusions}

This paper has analyzed the diurnal variation of nearsurface parameters from the 1987 FIFE data set. We showed a four-month average divided into "wet" and "dry" days. The wet group is significantly moister than the dry group and has a smaller diurnal temperature range, because of reduced net surface available energy. The diurnal cycle for the dry days for different months are very similar, although there are some differences in detail. The pressure height of the LCL, corresponding to cloud base in the afternoon, generally increases from May to October. The maximum $\theta_{E}$ reached during the day is largely controlled by the seasonal warming of soil temperature, modulated by the daytime surface heating. The mean rise of $\theta_{E}$ during the daytime is $14 \mathrm{~K}$ in midsummer.

We then partitioned a group of 94 dry days for which we

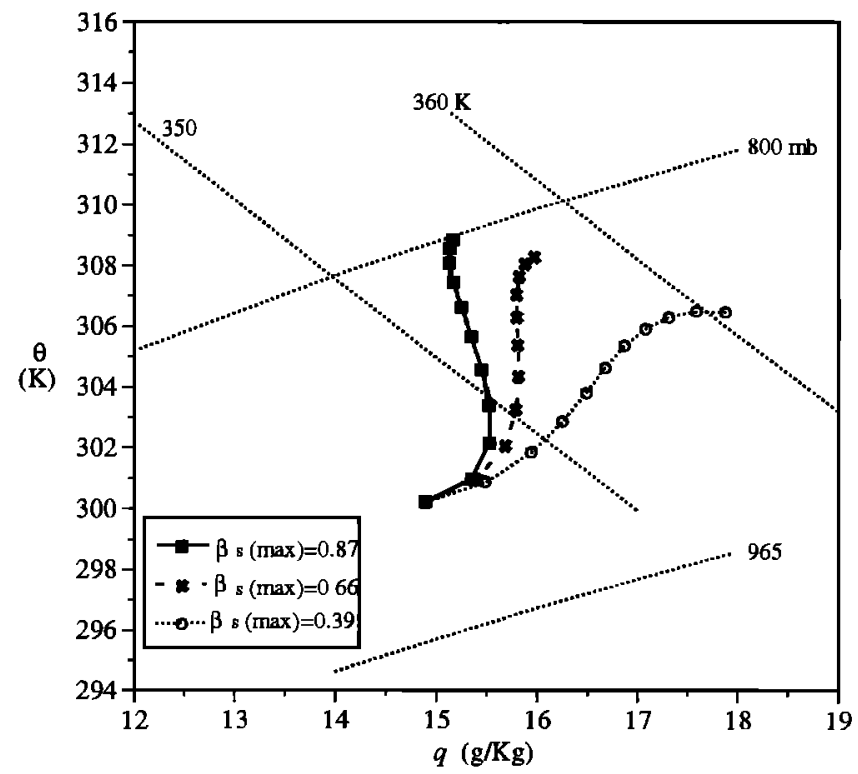

Figure 26d. As Figure 26b for $\beta_{t}=-0.35$. had soil moisture measurements and surface energy flux measurements. The partition by soil moisture showed a progression in structure on a $(\theta, q)$ plot. With decreasing soil moisture, the diumal temperature range increases, mixing ratio fell more in the afternoon, and the LCL rose more. Over a wide range of moderately wet soils, surface Bowen ratio $\beta_{s} \approx 0.35 \pm 0.15$ at local noon. Only with dry soil moistures ( $<20 \%$ by volume) did $\beta_{s}$ rise. Partitioning the data by $\beta_{s}$ rather than soil moisture gave similar composites, but nearly two thirds of the days fall into one category of unstressed evapotranspiration. To explore this further, we then binned averaged data for a 3-hour period, 1700 to 2000 $\mathrm{UT}$, close to local noon against soil moisture and surface Bowen ratio. The $\beta_{s}$ stratification suggested that the lowest values of $\beta_{s}$ are related not to the wettest soils but to evaporation being forced by a dry BL above. This was confirmed by superimposing these data on solutions of the Penman-Monteith equation as a function of soil moisture and $\boldsymbol{P}_{\mathrm{LCl}}$. For dry soils the reduced surface evaporation also results in a dry aftemoon $B L$.

Our final partition was to select 28 days in July and August, which were affected little by strong cold advection, and composite these by soil moisture. Although each group now comprises only about 10 days, this gave the clearest separation of the surface thermodynamic cycle. With increasing soil moisture, again the diurnal temperature range decreased, but now the diurnal range of $\theta_{E}$ increased. The afternoon equilibrium $\theta_{E}$ over the wet soils, when the vegetation is unstressed reaches $361 \mathrm{~K}$, in contrast to only $353 \mathrm{~K}$ over the driest soils. Correspondingly, the pressure height of the LCL is much lower: only $140 \mathrm{mb}$ over wet soil, as opposed to $240 \mathrm{mb}$ over the driest soils.

Mixed layer model solutions were compared with these FIFE soil moisture composites for the 28 days in July and August. Using the measured surface BRs and estimates of entrainment $A_{R}$ and ML-top BR $\beta_{\mathrm{i}}$ from BB94, we were able to reproduce qualitatively the observed diurnal cycle. We showed the strong sensitivity to ML-top entrainment, and $\beta_{i}$, and again concluded that high entrainment was necessary $\left(A_{R} \approx 0.4\right)$ to reproduce the observed FIFE diumal cycle. It is clear that although the ML model is a useful tool, more work needs to be done on the coupling between cloud and subcloud layers over land to model satisfactorily the fully coupled land surface-BL system. This equilibrium controls the evolution of the BL-cloud field and can determine the location of precipitation convection. The link between soil moisture and afternoon $\theta_{E}$ equilibrium is a critical part of the local surface boundary control on atmospheric convection over land. As over the oceans, the seasonal cycle of surface temperature plays a major role in the afternoon $\theta_{E}$ equilibrium. Unlike over the oceans, variations in soil moisture in summer produce important variations in BL equilibrium $\theta_{E}$. Soil moisture also provides a long-term memory (separate from surface temperature) from the weekly to seasonal timescales (and for deeper layers at interannual timescales). If soils are moist over large enough horizontal scales, then the associated higher equilibrium $\theta_{E}$ and lower cloud-base can be expected to organize mesoscale convective systems, just as warmer sea surface temperatures do over the ocean. More generally, improvements in our representation of the surface boundary condition over land are likely to yield major improvements in both climate and forecast models. 
Acknowledgments. This work has been supported by NASA-GSFC under contract NAS5-32334 and NSF under grant ATM90-01960. The FIFE experiment involved the cooperation of many. We are particularly grateful to Eric Smith for his surface flux time series and for useful discussions.

\section{References}

Betts, A. K., Non-precipitation cumulus convection and its parameterization, Q.J.R. Meteorol. Soc., 99, 178-196, 1973.

Betts, A. K. The thermodynamic transformation of the tropical subcloud layer by precipitation and downdrafts. J. Atmos. Sci., 33, 1008-1020, 1976.

Betts, A. K. , Boundary layer thermodynamics of a High Plains severe storm, Mon. Weather Rev., 112, 2199-2211, 1984.

Betts, A.K. , FIFE atmospheric boundary layer budget methods, J. Geophys. Res., 97., 18,523-18,531, 1992.

Betts, A.K., Relation between equilibrium evaporation and the saturation pressure budget, Boundary-Layer Meteorol., in press, 1994.

Betts, A.K., and J.H. Ball, Budget analysis of FIFE 1987 sonde data, J. Geophys. Res., 99, 3655-3666, 1994.

Betts, A.K., and J. Bartlo, The density temperature and the dry and wet virtual adiabats. Mon. Weather Rev., 119, 169-175.

Betts, A.K., J.H. Ball, and A.C.M. Beljaars, Comparison between the land surface response of the European Centre model and the FIFE 1987 data, Q. J. R. Meteorol. Soc., 119, 975-1001, 1993.

Carson, D.J., The development of a dry inversion-capped convectively unstable boundary layer, Q.J.R. Meteorol. Soc., 99, 450-467, 1973.

Clarke, R. H., Modelling mixed layer growth in the Koorin experiment, Aust. Meteorol. Mag. 38, 227-234, 1990.

Crosson, L.C., and E.A. Smith, Estimation of surface heat and moisture fluxes over a prairie grassland, 2, Two-dimensional time filtering and site variability, J. Geophys. Res., 97, 18,582-18,598, 1992

Culf, A. D., An application of simple models to Sahelian convective boundary layer growth Boundary Layer Meteorol. 58, 1-18, 1992.

Culf, A.D., Equilibrium evaporation beneath a growing convective boundary layer, Boundary Layer Meteorol, 60, in press, 1994.

Dickinson, R.E., Modelling evapotranspiration for three dimensional global climate models, in Climate Processes and Climate Sensitivity, Geophys. Monogr. Ser. 29, Edited by J.E. Harrison and T. Takahashi, pp.58-72, AGU, Washing ton D. C., 1984.

Grossman, R.L., Convective boundary layer budgets of moisture and sensible heat over an unstressed prairie, $J$. Geophys. Res., 97, 18,425-18,438, 1992.

Kanemasu, E.T., et al., Surface flux measurements in FIFE: An overview, J. Geophys. Res., 97, 18,547-18,555, 1992.

Kim, J., and S.B. Verma, Components of surface energy balance in a temperate grassland ecosystem, Boundary Layer Meteorol. 51, 401-417, 1990.

Monteith, J.L., Evaporation and surface temperature, Q.J.R. Meteorol. Soc., 107, 11-27, 1981.

Sellers, P.J., W.J. Shuttleworth, J.L. Dorman, A. Dalcher, and J.M. Roberts, Calibrating the simple biosphere model (SiB) for Amazonian tropical forest using field and remote sensing data, I, Average calibration with field data, J. Appl. Meteorol., 28, 727-759. 1989.

Sellers, P.J., and F.G. Hall, FIFE in 1992: Results, scientific gains, and future research directions, J. Geophys. Res., 97, 19,091-19,109, 1992

Smith, E.A., et al., Area-averaged surface fluxes and their time-space variability over the FIFE experimental domain, J. Geophys. Res., 97, 18,599-18,622, 1992a.

Smith, E.A., W.L. Crosson, and B.D. Tanner, Estimation of surface heat and moisture fluxes over a prairie grassland, 1 , In situ energy budget measurements incorporating a cooled mirror dew point hygrometer, J. Geophys. Res., 97, 18,557$18,582,1992 b$.

Stewart, J.B., and S.B. Verma, Comparison of surface fluxes and conductances at two contrasting sites within the FIFE area, J. Geophys. Res., 97, 18623-18628, 1992.

Strebel, D. E., D.R. Landis, K.F. Huemmrich, and B.W. Meeson, 1994: Collected data of the First ISLSCP Field Experiment, in Surface Observations and Non-Image Data Sets,. vol. 1, CD-ROM, NASA Goddard Space Flight Center, Greenbelt, MD.

Stull, R.B., An Introduction to Boundary Layer Meterology, 666 pp., Kluwer Academic, Norwell, Mass., 1988.

Tennekes, H., A model for the dynamics of the inversion above a convective boundary layer, J. Atmos. Sci., 30, 558-567, 1973.

Verma, S.B., J. Kim, and R.J. Clement, Momentum, water vapor, and carbon dioxide exchange at a centrally located prairie site, J. Geophys. Res., 97, 18,629-18,641 1992.

A.K. Betts and J.H. Ball, Atmospheric Research, RR 3, Box 3125, Pittsford, VT 05763.

(email: betts@boris.gsfc.nasa.gov)

(Received February 21, 1994; revised October 18, 1994; accepted November 14, 1994.) 